NASA Technical Memorandum 104440

AIAA-91-1305

$$
1 N-18
$$

p 39 .

\title{
Preliminary Thermal Design of the COLD-SAT Spacecraft
}

Hugh Arif

Lewis Research Center

Cleveland, Ohio

(NASA-TM-104440) PRELIMINAPY THERMAL OESIGN
OF THE COLD-SAT SPACECRAFT (NASA) $39 \mathrm{P}$

CSCL 228

N91-25161

\section{$63 / 19 \quad 0019782$}

Prepared for the

26th Thermophysics Conference

sponsored by the American Institute of Aeronautics and Astronautics

Honolulu, Hawaii, June 24-26, 1991 


\title{
Preliminary Thermal Design of the COLD-SAT \\ Spacecraft
}

Hugh Arif

National Aeronautics and Space Administration

Lewis Research Center

Cleveland, Ohio 44135

\begin{abstract}
The COLD-SAT free-flying spacecraft was to perform experiments with $\mathrm{LH}_{2}$ in the cryogenic fluid management technologies of storage, supply and transfer in reduced gravity. This paper describes the Phase A preliminary design of the Thermal Control Subsystem (TCS) for the spacecraft exterior and interior surfaces and components of the bus subsystems. The TCS was composed of passive elements which were augmented with heaters. Trade studies to minimize the parasitic heat leakage into the cryogen storage tanks have been described.

Selection procedure for the thermally optimum on-orbit spacecraft attitude has been defined. TRASYS-II and SINDA'85 verification analysis was performed on the design and the results are presented here.
\end{abstract}

\section{NOMENCLATURE}

$\begin{array}{ll}\text { ACS } & \text { Attitude Control Subsystem } \\ \text { BOL/EOL } & \text { Beginning/End of Life } \\ \text { DTC } & \text { Dual Temperature Controller } \\ \text { HGA/LGA } & \text { High/Low Gain Antenna } \\ \text { Liquid Hydrogen } \\ \text { LH } & \text { Lidi-layer Insulation } \\ \text { MLI } & \text { Multion } \\ \text { OSR } & \text { Optical Solar Reflector } \\ \text { TCS } & \text { Thermal Control Subsystem } \\ \text { TT\&C } & \text { Telemetry, Tracking and Command } \\ \alpha & \text { Absorbtivity } \\ \beta & \text { Beta Angle, degrees } \\ \epsilon & \text { Emissivity }\end{array}$

\section{INTRODUCTION}

The COLD-SAT (Cryogenic On-Orbit Liquid Depot - Storage, Acquisition and Transfer) spacecraft was being developed by NASA Lewis to conduct experiments in reduced-gravity cryogenic fluid management. The COLD-SAT spacecraft has recently completed Phase $A$ concept design studies by parallel contracted efforts with three contractors. At the same time, a similar study has been completed by 
an in-house design group at NASA Lewis. This paper describes the results of the TCS preliminary design at the end of this Phase A for the in-house study. Further efforts to develop the COLD-SAT spacecraft to conduct in-space experiments have been halted due to the high projected costs of the spacecraft. However, the COLDSAT spacecraft and the TCS incorporated some unique design features which should be of general interest to the aerospace community.

The spacecraft would have performed experiments with $\mathrm{LH}_{2}$ over a six month period after launch. Experiments were to be conducted in various technologies associated with the storage, supply and transfer of $\mathrm{LH}_{2}$ in space. These experiments were to provide test data to validate analytical math models presently being developed. These validated models would then be used to develop criteria for the design of efficient cryogenic systems and components that are essential in propulsion and life support functions for future NASA missions.

The thermal design requirements for each of the five modules of the COLDSAT spacecraft were extremely diverse. The TCS design described herein had been customized for the temperature and thermal requirement for each of these five modules. Since the $\mathrm{LH}_{2}$ was a valuable commodity on board the spacecraft, it was essential to store this cryogen for the duration of the experiments. This was achieved by minimizing the parasitic heat leakage into the cryogenic system. This required maintaining minimum temperatures on all components, that were either conductively or radiatively coupled to the cryogenic storage tanks. On the other hand, efficient operation of components of the spacecraft bus subsystems required that the temperature of the electronics boxes, hydrazine $\left(\mathrm{N}_{2} \mathrm{H}_{4}\right)$ and batteries be as close to room temperature as possible.

As described in this paper, these diverse requirements were fulfilled by the design of a unique spacecraft TCS which was composed mainly of passive components. The only active components were thermal control heaters that augmented the passive design. The exterior thermal design that was developed, protected the spacecraft and its components from the orbital environmental fluxes, while maximizing the use of these fluxes to reduce heater requirements. The use of the space heat sink had been maximized in the exterior thermal design of the cryogenic components. The interior thermal design of the Electronics Bays maximized the use of power dissipation from each electronics box to reduce heater power. The thermal components of the spacecraft were all existing, flight qualified hardware consisting of MLI blankets, thermal coatings, surfaces and finishes, thermal conduction enhancers and insulators, and OSRs. Mounting details of electronics boxes, $\mathrm{N}_{2} \mathrm{H}_{4}$ tanks, and batteries were developed for either conduction coupling or decoupling in order to satisfy specific temperature requirements.

Geometric and thermal math models were developed, both for the exterior and interior surfaces and for the components of the spacecraft. This thermal design was analytically verified by the use of these math models. Temperature predictions were made for all components, and the capability of the TCS to 
maintain the component temperatures in compliance with the specification provided for by the various subsystems was verified analytically. Four on-orbit mission conditions and phases were analyzed, and the TCS viability verified for each. Heater power was calculated for make-up, load substitution and survival temperature conditions for each electronics component.

For an initial trade on the effects of the spacecraft thermal design on the heat leak into the largest $\mathrm{LH}_{2}$ storage tank, the Supply Tank, geometric and thermal math models were developed for its module. Parametric studies with various thermal control materials were performed to determine impacts on heat leakage before a final selection on the outer surface material for this and the other $\mathrm{LH}_{2}$ tanks was made. Another trade was performed on the spacecraft attitude impacts on the thermal performance of this Supply Tank. The results of this study was one of the criteria by which the final COLD-SAT spacecraft altitude for this study was selected.

Materials for the spacecraft TCS were selected based on consideration of availability, heritage, cost, weight and reliability. The preliminary selected thermal design has been documented in this paper.

\section{SPACECRAFT DESCRIPTION}

The Lewis version of the COLD-SAT spacecraft, shown in Fig. 1 and described in Ref. 1, was estimated to weigh approximately 6600 pounds and would be launched by an Atlas-Centaur into a $18^{\circ}$ inclination, $550 \mathrm{NM}$ low-earth circular orbit from Cape Kennedy. At this inclination, the sun makes a $\beta$ angle of $\pm 41^{\circ}$ relative to the orbit plane. The orbit has a period of 105.46 minutes, nodal regression rate of $\mathbf{5 . 6 6}$ degrees/day and eclipse times ranging from 28 to 35 minutes. COLD-SAT was a 3 -axis stabilized spacecraft and was configured for a $11 \mathrm{ft}$ diameter payload fairing.

The spacecraft had all the usual housekeeping subsystems of Structural, TCS, TT\&C, ACS, Power and Propulsion. In addition, there was an Experiment Subsystem that was comprised of $\mathrm{LH}_{2}$ tankage, two independent pressurization systems, electronics boxes, instrumentation and fluid handling components. For the purpose of easy assembly and maintenance, the spacecraft had been configured in a modular design, consisting of five separate modules (Fig. 2). Each module was independently supported by its longerons. Three of the modules form the Experiment Subsystem which consisted of the cryogenic $\mathrm{LH}_{2}$ tankage and components, and the other two were modules for the spacecraft bus subsystems. The bus modules consisted primarily of electronics boxes, attitude control sensors, $\mathrm{N}_{2} \mathrm{H}_{4}$ tanks, lines and thrusters for Propulsion and batteries for the Power Subsystem. These modules were, beginning from the spacecraft aft end: Electronics Bay No. 1, Supply Tank, Electronics Bay No. 2, Receiver Tank No. 1 and Receiver Tank No. 2. The five modules, when coupled to and supported by the Structural Subsystem, formed the complete spacecraft. 
Electronics Bay Modules. The Electronics Bay No. 1 (EB1) module weighed $745 \mathrm{lb}$ and consisted of mostly electronics boxes and batteries which were mounted on the sidewalls of the Bay (Fig. 3). It also included four, 22-inch diameter propellant tanks containing $600 \mathrm{lb}$ of $\mathrm{N}_{2} \mathrm{H}_{4}$ and other components of the Propulsion Subsystem. These tanks were mounted on a plate located in the center of the Bay. On four of the eight sidewalls were mounted propulsion thrusters to provide the required attitude control and low-g axial thrusting. In addition, there was a gimballed thruster for performing bi-axial thrusting with a maximum gimbal axis of $\pm 15^{\circ}$ per axis. Sun sensors and their electronics were also located here. The Electronics Bay No: 2 (EB2) was similar in design to the EB1, but only contained electronics boxes which were mounted on the bay sidewalls. Horizon sensor optics and electronics were also located here (Fig. 4). This module weighed $262 \mathrm{lb}$.

Supply Tank Module. This module weighed $1696 \mathrm{lb}$. and consisted of a 144 $\mathrm{ft}^{3}, \mathrm{AL} 5083$ pressure vessel (PV) which supplied fluid to other subsystem components (Fig. 5). It was cylindrical with ellipsoidal dome ends and, when filled to a $92 \%$ fill level, contained $565 \mathrm{lb}$ of $\mathrm{LH}_{2}$ at 20 psia. It was supported by fiberglass struts which attached to its girth rings. The PV was surrounded by a aluminum "can" which supported a MLI blanket and thermally isolated the PV from direct MLI radiation and conduction. The "can" consisted of 3/8-in. AL 5056 core and was supported off the tank support struts by sleeves at a distance of 2-in. from the PV. External to the MLI layers was a purge diaphragm which contained the GHe used to purge the volume between the diaphragm and the PV, including the MLI. Purging would be performed before filling the PV with $\mathrm{LH}_{2}$ to prevent the liquefaction of air on the tank and related surfaces prior to launch.

An AL 6061 Plumbing Tray (Fig. 6) was located just outside the spacecraft structure and contained the plumbing and wiring harnesses for the cryogen tanks. Also in the module were two, 2000 psia, SS 304 hydrogen vaporizer bottles with a storage capacity of $3.5 \mathrm{lb}$ of $\mathrm{LH}_{2}$ each. These vaporizers produced gas from $\mathrm{LH}_{2}$ withdrawn from the Supply Tank for autogenous pressurization prior to transfer. In addition to the vaporizers, two 3000 psia, filament wound, metal lined composite bottles stored $8.5 \mathrm{lb}$ of $\mathrm{GHe}$ to provide another source of pressurant. In keeping with the modular concept, individual plumbing and electrical components for the Experiment Subsystem were mounted on several panels based on functional requirements.

Attached to the Supply Tank module longerons were two fixed solar arrays, canted at an optimum $13^{\circ}$ angle to reduce the cosine $\beta$ angle penalty of solar flux on power generation. The array had a $2050 \mathrm{~W}$ BOL peak power capability with a $190 \mathrm{ft}^{2}$ total area. A HGA was also mounted off the longerons on a boom, through which TDRSS communication was to be established $13 \mathrm{~min}$ per orbit for downlink of data.

Receiver Tank Modules. The Large Receiver Tank module weighed $263 \mathrm{lb}$ 
and consisted of a $21 \mathrm{ft}^{3}$ non-vacuum jacketed insulated tank. The tank was cylindrical with ellipsoidal heads. The Small Receiver Tank module weighed $200 \mathrm{lb}$ and was similar to the previous module (a cylindrical, $13.5 \mathrm{ft}^{3}$ tank with ellipsoidal heads). Both tanks were made of AL 5083, had a 0.5-in. thick honeycomb "can" which surrounded the PV and were each supported by S-2 glass/epoxy struts from the module longerons.

\section{SPACECRAFT ATTITUDE SELECTION}

Since the COLD-SAT spacecraft was comprised of cryogenic components, an important consideration in spacecraft thermal design was to minimize the parasitic heat leakage into the three $\mathrm{LH}_{2}$ tanks. Initial studies had indicated that, among the PV heat leak contributors for the Supply Tank, the manganin instrumentation wiring, Al power wiring and SS304 plumbing lines were the major contributors. Therefore, it was decided to route all wiring and plumbing lines on the Plumbing Tray that was to be located on a side of the spacecraft that was minimally impacted by solar flux, and would thus be at a lowest possible temperature. This tray was conductively isolated from the spacecraft structure and was radiatively cooled to space to achieve cold temperatures. From the concept of modularity in the COLD-SAT spacecraft design, individual plumbing and wiring harness components were distributed onto several panels, grouped by their functional requirements. Some of these panels had to be maintained in a warm environment, and were therefore located on the "hot" side of the spacecraft. Remaining panels were located on the spacecraft "cold" side to take advantage of the lack of solar flux and to remain as cold as possible, for cryogenic tankage parasitic heat leakage reduction. The spacecraft was, therefore, to be thermally bifurcated into a "hot" and a "cold" side (Fig. 7).

This bifurcation was achieved by constraining the solar arrays to be of a fixed, non-articulating type so that only sun-tracking, "quasi-inertial" attitudes were possible. In these attitudes, the spacecraft was oriented to have the fixed arrays constantly face the sun while rotating about one of its axis to track the sun at one revolution per year. With only quasi-inertial attitudes as the optimum thermal orientations for the cryogenic tankage and components, two specific attitudes were possible, as indicated in Fig. 8. These attitudes resulted in large portions of the spacecraft becoming incident to the solar flux, thereby creating a "hot" side of the spacecraft. Considerably higher temperature excursions occured on this "hot" side as compared to the other anti-sun side. The anti-sun side, being exposed to radiation to space and the comparatively lower earth albedo and infra-red fluxes, acted as a "cold" side and thus performed in lower temperature ranges. Trade studies were conducted on the impact of each of these two possible attitudes on the cryogenic performance of the Supply Tank. The attitude with the least thermal impact resulting in the lowest heat leakage into the Supply Tank PV was to be selected. 
In one of the attitudes under consideration, named Attitude "A" (Fig. 8a), the long axis (x-axis) of the spacecraft was co-planer with the orbit plane. The fixed solar arrays were canted at an optimized $13^{\circ}$ to orbit normal. When the angle of the sun line to the orbit plane ( $\beta$ angle) was $0^{\circ}$, the spacecraft EB1 module shielded the Supply Tank and other tanks from solar flux. This provided the coldest tank thermal condition for this attitude. As the sun travelled to the maximum of $\beta=41^{\circ}$ (for the selected orbital inclination of $18^{\circ}$ ), the projected area of the Supply Tank to the sun line was impacted from solar flux. This created the warmest environment for this attitude.

The wide variation in the surface temperatures of the Supply Tank resulting from the $\beta=0$ to $\beta= \pm 41$ thermal conditions are shown in Fig. 9.

For the $\beta=0^{\circ}$ case, since the solar flux was in line with the long axis of the spacecraft, there was no solar flux impact on the Supply Tank. Consequently, the average temperature profile of the sun facing or "hot" side and the anti-sun or "cold" side were similar $\left(-85^{\circ} \mathrm{F}\right.$ to $\left.-140^{\circ} \mathrm{F}\right)$. However, for the $\beta=41^{\circ}$ case, when the sun was no longer colinear with the spacecraft long axis, the sun facing side of the Supply Tank increased to as high as $+10^{\circ} \mathrm{F}$ whereas the anti-sun or "cold" side went up to only $-80^{\circ} \mathrm{F}$.

The other possible attitude investigated herein was referred to as Attitude "B" in which the spacecraft long axis was normal to the orbit plane. The fixed solar arrays were canted as before. By rotating the spacecraft around its Z-axis, as shown in Fig. 8b, arrays remained sun pointed for $\beta= \pm 41^{\circ}$. For $\beta=0$, the solar flux impacted the projected Supply Tank area broadside. This produced the warmest environment for the Supply Tank. For the maximum $\beta= \pm 41$, the least projected area was available for the solar flux, hence the coldest conditions for the tank.

For establishing spacecraft attitude dependent heat leaks into the Supply Tank it was important to determine the hot boundary condition for each of the sources of parasitic heat leaks: (1) purge diaphragm for the MLI, (2) spacecraft structure for the tank support struts and (3) the Plumbing Tray for the wiring and plumbing. The spacecraft and Supply Tank TRASYS- 11 and SINDA' 85 models were performed for this analysis. The analysis results for the attitudes of interest are presented in Fig. 10 for the purge diaphragm where the surface temperature is plotted versus orbital time.

The profiles for the average temperature of the eight structural longerons and also the Plumbing Tray were found to be constant. These values are tabulated in Table 1 below. For the Attitude "A", $\beta=0^{\circ}$, due to the lack of solar flux, both the longerons and tray were identical at $-102^{\circ} \mathrm{F}$. However, as the sun angle goes to $\beta=41^{\circ}$, the longeron average temperature rises to $-44^{\circ} \mathrm{F}$. Since the tray is on the anti-sun or "cold" side, it remains at a stable $98^{\circ} \mathrm{F}$. Temperatures for both components increased tremendously for the Attitude "B". 
It can be seen that the Attitude "A" for a $\beta=0^{\circ}$ had the lowest temperature due to the blocking of the solar flux by the aft end of the spacecraft. This temperature increased for the $\beta=41^{\circ}$ cases, since the sun was now impinging more broadside on the Supply Tank. The temperature profile for the Attitude "B", $\beta=0^{\circ}$ and $41^{\circ}$ was slightly higher at its peak than the $\beta=0^{\circ}$ case. It can be surmised that this was due to the forward end of the purge diaphragm being heated through the central cavity of the EB2 at this high $\beta$ angle. It could also have been due to a higher radiation contribution from the front MLI of the EB1.

From the Supply Tank results, it was evident that by placing the Plumbing Tray on the spacecraft "cold" side, much less parasitic heat leakage through the plumbing lines and wiring into the Supply Tank would occur. As shown in Fig. 11, there was minimal $\left(4^{\circ} \mathrm{F}\right)$ change in the Plumbing Tray temperature regardless of the $\beta=0$ or $\beta=41^{\circ}$ orbital conditions.

Total average heat fluxes on the Supply Tank PV are presented in Fig. 12 for the four extreme cases. It was evident that for the thermal design used in this analysis, the Attitude " $A$ " best case of $\beta=0^{\circ}$ produced a 48 percent lower heat flux $\left(0.0559 \mathrm{Btu} / \mathrm{hr}-\mathrm{ft}^{2}\right)$ relative to the $\beta=41^{\circ}$ case for Attitude "B" (0.0826). Comparably, the $\beta=41^{\circ}$ worst case for the worst case for the Attitude "A" (0.0728) produced a 22 percent lower heat flux than $\beta=0^{\circ}$ for Attitude "B" (0.0891). Attitude "A" was consequently selected as the nominal COLD-SAT spacecraft attitude. Further discussion is given in Ref. 2.

In a six month period, given the COLD-SAT orbital parameters and for any launch window, the sun will cross the orbital plane a maximum of five times. To maintain the "hot"/"cold" side restriction on the spacecraft periphery, the spacecraft will have to perform a $180^{\circ}$ roll maneuver around its long axis whenever the sun crosses the orbit plane. This is necessary to ensure that the same side of the spacecraft would remain in view of the sun at $\beta=41^{\circ}$, and also to keep the arrays generally sun-pointed.

\section{TCS DESIGN PHILOSOPHY}

The COLD-SAT TCS was designed in accordance with the design philosophy of utilizing simple, flight-proven thermal control hardware to maintain acceptable component temperatures with adequate margins during all mission phases.

Temperatures were controlled by techniques derived from previous spacecraft programs, featuring primarily conventional passive design elements augmented as required by proportionally controlled heaters. Passive design components included MLI blankets, selected surface finishes, foils and tapes, conductioncoupled/decoupled mounting details and OSRs. Louvers and heat pipes were not considered due to the consideration of increased cost, decreased reliability and complicated integration. Active components included resistance heaters, thermistors and autonomous dual temperature heater controllers. This approach 
provided simple, yet highly reliable, temperature control for all mission conditions.

The TCS was designed to perform under the worst-case combination of external environment and equipment power dissipations to be experienced by the spacecraft. The subsystem provided a margin of $35^{\circ} \mathrm{F}$ above and $20^{\circ} \mathrm{F}$ below the minimum and maximum component non-operating temperatures, respectively, for operation under all mission conditions. These conditions accounted for EOL electrical power availability and variation in environmental fluxes, as well as degradation in surface properties. Since COLD-SAT was a cryogenic experimentation spacecraft, minimization of boil-off losses to enhance cryogen storage life was an important consideration. Every attempt was made to reduce the heat leaks into the $\mathrm{LH}_{2}$ Supply and Receiver Tanks by lowering the hot side boundary temperatures of these leak paths.

The heater power was minimized for all mission phases. Survival heaters for pre-operational housekeeping heater power and make-up heater power during eclipses were minimized. In addition, electronics box back-up heaters did not provide additional load to the Power Subsystem. These back-up heaters were to be turned on only to maintain non-operating temperatures on electronics boxes, when these boxes are non-operating. The TCS design approach did not require that restrictions be placed on the electronics operating duty cycles, which was $100 \%$ for all components. Commandable back-up heaters for load substitution were configured to accommodate a broad range of operational conditions for loss of power and also seasonal conditions.

The performance of the MLI blanket design for cryogenic applications was based on previously flown and qualified hardware heritage configuration from the IRAS and COBE spacecraft programs, rather than ground based laboratory studies. The performance of the spacecraft thermal control blankets was based on effective $\epsilon$ data that is unpublished but verified by testing and flight performance by a major aerospace contractor. BOL data for optical thermo-physical properties of MLI was considered in the design due to the short duration of the mission. No degradation for outgassing, solar illumination, plume effects and electrostatic charging were included.

While the TCS provided thermal control for all spacecraft components, control requirements for certain critical elements were key factors in the design, and are worthy of particular note:

1. For the Experiment Subsystem Supply Tank Module, total average heat leak into the PV from all conductive and radiative sources had to be less than 0.1 $\mathrm{Btu} / \mathrm{hr}-\mathrm{ft}^{2}$ (based on Supply Tank PV wall area). To achieve this goal, the purge diaphragm outer surface had to be maintained as cold as possible to reduce MLI radiative heat leaks. In addition, the spacecraft structure, off which the Supply Tank is supported, had to be maintained as cold as possible to reduce parasitic conductive heat leaks through the tank support struts. The Plumbing Tray, from 
which all plumbing and wiring harnesses proceed to the Supply Tank, had to be maintained as cold as possible to minimize parasitic conduction. The two receiver tanks of the Experiment Subsystem had average heat leak design goals of 0.5 $\mathrm{Btu} / \mathrm{hr}-\mathrm{ft}^{2}$. Since these were higher than the Supply Tank heat leak goal, the Supply Tank was considered to be the design driver for tankage outer surface material selection.

2. For the Propulsion Subsystem, the $\mathrm{N}_{2} \mathrm{H}_{4}$ storage tanks and the GHe pressurant bottles were to be maintained above $40^{\circ} \mathrm{F}$, allowing ample margin above the freezing point temperatures of $\mathrm{N}_{2} \mathrm{H}_{4}\left(34.8^{\circ} \mathrm{F}\right)$. Temperature differences between interconnected tanks were maintained below $10^{\circ} \mathrm{F}$ to preclude significant changes in spacecraft center of mass resulting from thermally induced flows. However, heater power requirements were to be minimized by tank layout and passive control, allowing for the maximum use of available power from the spacecraft electronics dissipation and making power available for other uses.

3. For the Power Subsystem, to maintain optimal performance and recharge capability throughout mission life, the nickel-cadmium batteries were to be maintained within their preferred operating temperature range of $30^{\circ}$ to $85^{\circ} \mathrm{F}$.

4. For the TT\&C Subsystem, thermal distortion of antenna reflectors and their supports was minimized to reduce associated radio frequency (RF) losses.

\section{TCS ANALYTICAL MODELS}

The COLD-SAT Spacecraft TCS was analyzed using NASA standard computer codes, using which detailed geometric and thermal models were developed. All analysis was performed for the selected attitude "A" for the spacecraft. The TRASYS-II code was used to calculate radiation coupling factors for spacecraft exterior and interior surfaces. Also calculated were absorbed onorbit heat fluxes of solar, earth albedo and earth infra-red on the exterior surfaces for several $\beta$ angle orientations, as described previously. The spacecraft geometry was sub- divided into six groupings and a TRASYS-II geometric model was developed for the radiation analysis of each group. These six groups are: all spacecraft exterior surfaces; EB1 exterior and interior; EB2 exterior and interior; and the Structural Subsystem. The outputs from each of the six models were combined to form the inputs for the spacecraft-level thermal analysis.

The thermal analysis was performed using the SINDA' 85 code into which TRASYS-II inputs were provided to complete the physical design description of the spacecraft. Here, additional hand calculated radiative couplings were combined with the SINDA'85 mathematical description of the nodes for thermal capacitance, equipment thermal dissipations and conductive couplings. This information permitted spacecraft thermal balance computations to be made for specific attitudes and operational conditions of interest. The SINDA' 85 output included spacecraft and Experiment Subsystem component temperatures and heater power 
predictions based on equipment power dissipations and temperature ranges specified. From a manageability consideration, four SINDA'85 thermal math models were developed: all spacecraft exterior surfaces; EB1 and EB2 interior and exterior; and the Structural Subsystem. After debugging of each model, these four models were combined for final results at the overall spacecraft level.

Four spacecraft orbital conditions (Fig. 13) were evaluated to determine the viability of the TCS design. Hot case $\left(\beta=41^{\circ}\right)$, Cold Case $\left(\beta=0^{\circ}\right)$, Loss of Attitude Case $\left(\beta=0^{\circ}\right.$, with the spacecraft long axis normal to the orbit plane, and sun incident on the battery panel), and Load Shedding Case $\left(\beta=0^{\circ}\right.$, and zero power dissipation from electronics). Make-up heater power requirements were calculated to maintain components within their operating temperature ranges. Survival heater requirements were calculated to maintain electronics at cold start temperature $\left(-5^{\circ} \mathrm{F}\right)$ and the $\mathrm{N}_{2} \mathrm{H}_{4}$ above freezing $\left(40^{\circ} \mathrm{F}\right)$, for the case of spacecraft bus load shedding situation. To increase conduction from the electronics boxes to the mounting honeycomb panels, Chotherm 1671 conduction enhancers were used and modelled. Also, EB1 and EB2 were conductively isolated at the structure from the Experiment Tank Modules due to conflicting thermal control requirements and this isolation was also modelled.

The spacecraft altitude was modelled as 550NM with an orbit inclination of $18^{\circ}$ at which the $\beta$ angle range is $0^{\circ}$ to $41^{\circ}$. For the $\beta=41^{\circ}$, solar flux was modelled to be incident on the "hot" side of the spacecraft only. The values of solar flux, albedo and earth infra-red were $444 \mathrm{Btu} / \mathrm{hr}-\mathrm{ft}^{2}, 0.3$ and $77 \mathrm{Btu} / \mathrm{hr}-\mathrm{ft}^{2}$ respectively. Solar arrays were modelled as non-articulating, but canted at $13^{\circ}$ to orbit normal. The design life of the spacecraft is six months; consequently, only BOL thermo-optical properties were considered in this analysis.

The area of each OSR radiator was parametrically sized according to maximum solar flux, OSR solar $a(0.1)$ and maximum and minimum power dissipations. Initial estimates were obtained by hand calculations for thermal balance and parametric computer runs were performed with SINDA'85 to determine final areas. The heaters were sized by the HEATER subroutine in SINDA' 85 given the desired temperature set points.

Among all the mission phases that the COLD-SAT spacecraft would undergo, the "attitude acquire" phase and the "on-orbit peak" phase were identified as the lowest and the highest power dissipation phases, respectively. The on-orbit dissipation levels of all the COLD-SAT spacecraft components for these two phases are provided in Ref. 1. For conciseness, subtotals for each subsystem are given in Table 2. The lowest and the highest power dissipations are $547 \mathrm{~W}$ and $674 \mathrm{~W}$ respectively, as used in the analysis, and for which the TCS was designed. The attitude acquire dissipations were used to perform the cold case thermal analysis for $\beta=0^{\circ}$ and the on-orbit peak dissipation were used for the hot case analysis for $\beta=41^{\circ}$. Some spacecraft components such as the HGA Gimbal Motor and the Propulsion Subsystem valves and plumbing components were not 
included in the math models developed for the thermal analysis. The Gimbal Motor was at the end of a support boom and away from the other spacecraft components, and therefore, did not have any temperature effects on others. Similarly, the propulsion valves were also remote and operated intermittently. These components, however, did have their individual thermal control to maintain them within the temperature specifications.

The design temperatures of all the spacecraft components for the operational and non-operational ranges are documented in Ref. 1 and summarized in Table 3 here. The minimum non-operational temperature of $-5^{\circ} \mathrm{F}$ was selected as the cold start turn-on temperature for the electronics. It should be noted that the maximum temperatures for the Vent and Vaporizer Panels was based on the condition when there was no $\mathrm{LH}_{2}$ flowing through them. In summation, the electronics boxes were to be maintained between $30^{\circ}$ to $125^{\circ} \mathrm{F}$, the batteries within $30^{\circ}$ to $85^{\circ} \mathrm{F}$ and the $\mathrm{N}_{2} \mathrm{H}_{4}$ components within $40^{\circ}$ to $120^{\circ} \mathrm{F}$. The experiment $\mathrm{LH}_{2}$ tank outer surfaces, supports, plumbing and wiring were to be as cold as possible. Some of the experiment panels were to be as cold as possible, while others were to be kept relatively warm in room temperature conditions.

The analyses were performed with TRASYS-II and SINDA'85 on a VAX 8600 using ITPLOT, XPLOT and GRAPHWRITER for pre-processing of input and post-processing of results to develop presentation graphics. The spacecraft orbital conditions that were analyzed and the TRASYS model of the spacecraft exterior surfaces are shown in Fig. 13.

\section{EXTERIOR TCS DESIGN SELECTED}

Exterior thermal control was applied to those surfaces and areas of the spacecraft which were exposed to heat gain from the orbital fluxes of solar, earth albedo and infra-red and to heat loss by radiation to deep space. The exterior thermal control of the COLD-SAT spacecraft is shown in Fig. 14 and is described below:

Electronics Bays. The exterior surfaces of the Spacecraft EB1 and EB2 were covered by specific combinations of OSRs $(\alpha / \in 0.1 / 0.79)$ and $M L I$ to utilize the diurnal orbital environmental heat exchange for controlling the temperature of the components within the Bays. This MLI was used to radiatively and conductively decouple the Bays from heat gain from and loss to the environment and other portions of the spacecraft. Based on the selected on-orbit attitude of the spacecraft, the aft end of the EB1 was fixed towards the sun and was completely covered with MLI. (Several small cutouts would have to be made in the aft MLI blanket in places where the ELV payload attach fitting bolts to the spacecraft. White paint would be used in these locations in lieu of MLI).

The MLI would have 12 layers of double aluminized Kapton (DAK) interspersed with Dacron net spacers, with an effective $\epsilon$ of 0.025 through the blanket 
thickness. The outer layer of the MLI would have an $a / \in$ of $0.49 / 0.71$. Alternate layers of 1/4-mil double aluminized Kapton and Dacron net would be sandwiched between outer layers of 2-mil reinforced Kapton with inner surface aluminized. The layers would be sewn together with nylon thread, and large sections of blanket material would be joined to each other and to the spacecraft using Velcro zipper material. To avoid charge buildup on MLI surfaces, several 2-mil thick aluminum grounding straps would be attached with soft aluminum rivets to aluminized surfaces. In addition, the outer surface of the outer layer would be coated with Indium Tin Oxide (ITO) to prevent electrostatic charge buildup.

Outgassing of volatile compounds from MLI blankets during the mission would be minimized by pre-flight thermal vacuum decontamination bake-out. Remaining residual outgassing during the mission would be directed away from the sensitive OSR radiator surfaces by preferentially located venting holes.

The side panels of the Bays ( $E, W, N, S, N E, N W, S W, S E$ ) included selective placement of OSRs beneath components having high heat dissipations. OSR radiators on the external side surfaces of these Bays would provide the means for the external radiation of excess heat generated by the components that cannot be utilized for temperature control by the Bay internals. The front panel of the EB1 would have two additional OSR radiators for the two batteries. The OSR radiator surface area requirements were determined by parametric analysis to accommodate both the high and the low power dissipation cases and are presented in Table 4.

The OSRs would be second surface mirrors made from silver plated 0.006 -inch fused silica. Individual $1 \mathrm{in}^{2}$ mirrors would be placed 15-mils apart and bonded with electrically conductive blue solithane to the outer aluminum facesheets of the EB1 side panels. Of all potential radiation surfaces available for use in the COLDSAT spacecraft, OSRs were chosen because of the stability of their properties in the on-orbit environment for this critical application. Individual radiators have measured solar $\alpha$ values of 0.06 at BOL. The OSR system, including gaps between individual mirrors, would have a $\in$ of 0.75 and a BOL $\alpha$ of 0.09 . Some degradation in $a / \in$ results from ultraviolet radiation and particle fluence, as well as from induced contamination by thruster exhaust plumes and outgassing spacecraft materials. The OSR $a / \in$ conservative values used in the analysis reflect this degradation.

The remaining exterior areas of the two bays would also be covered with MLI. By using MLI, the EB2 would be radiatively decoupled from the Large Receiver Tank No. 2 which protrudes through the EB2 central cavity. Each Electronic Bay Module (Modules 3 and 5) was conductively decoupled from heat loss to the cryogenic Modules (Modules 1,2 and 4) via the spacecraft structure. This decoupling was achieved by the use of thermally isolating $1 / 2$-inch thick pads of G-10 fiberglass or Vespel located at the interfacing flanges of the structural longerons. Vespel was preferred due to its resistance to moisture absorption. The thermo-optical properties for each exterior thermal control surface and finish is 
presented in Fig. 14. All the side, front and aft panels of the two Bays were highly conduction coupled due to the use of Aluminum (Al) honeycomb core with Al facesheets. This high conduction facilitated the diffusion of heat from any source to prevent localized temperature excursions.

Experiment Tankage. The Experiment Tankage consisted of the $\mathrm{LH}_{2}$ Supply Tank, $\mathrm{LH}_{2}$ Receiver Tanks No. 1 and 2, two GHe pressurant bottles, the $\mathrm{GH}_{2}$ vaporizer and the $\mathrm{GH}_{2}$ accumulator. The PVs of the three $\mathrm{LH}_{2}$ tanks were each surrounded by an Al honeycomb sandwich "can" which supported a 30-layer MLI blanket. On the Supply Tank, external to the MLI layers was a purge diaphragm which contained the GHe used to purge the volume between the purge diaphragm and the PV, including the MLI. The purge diaphragm consisted of two Kevlar-cloth reinforced layers, separated by an embossed Kapton layer. The outer layer had a coating of second surface silverized Teflon (SSST, $a / \in 0.09 / 0.75$ ) in order to keep this outer layer at a lowest possible temperature. A lower temperature of the outer surface reduced the parasitic heat leak through the MLI to the "can". Further details of their design can be obtained from Ref. 3.

The two Receiver Tanks did not have a purge diaphragm since they were not loaded with $\mathrm{LH}_{2}$ at launch and, therefore, did not require purging of their MLI blankets or the PV on the ground. However, for reducing the parasitic heat leaks through the MLI while in orbit, both tanks had a similar SSST as the outer layer of the MLI. Additional sources of heat leaks into the $\mathrm{LH}_{2}$ tankage was conduction through tank support struts, power and instrumentation wiring harnesses and plumbing lines. Each of these conduction paths had a hot temperature boundary on the spacecraft which provided the unavoidable temperature difference for heat transfer into the cryogen. The spacecraft structure temperature represented the hot side boundary temperature for the tank support struts, and the Plumbing Tray temperature represented the hot side boundary temperatures for the wiring and plumbing lines routed to the tank. Thermal control of these items is described in the following two sections.

The $\mathrm{GHe}$ and $\mathrm{GH}_{2}$ bottles were each covered with a 12 layer DAK/Dacron MLI blanket, with a outer surface $a / \in$ of $0.41 / 0.50$. The $\mathrm{GH}_{2}$ bottles were located on the "hot" side of the spacecraft in order to reduce the heater requirements for vaporizing the $\mathrm{LH}_{2}$ to gas. In contrast, the $\mathrm{GHe}$ bottles were maintained as cold as possible on the "cold" side of the spacecraft. All four bottles were decoupled from their support structure by thermally isolating G-10 or Vespel Pads, as described previously.

Spacecraft Structure. Distortion of the spacecraft exterior support structure due to changes in orbital fluxes at sunrise and sunset was minimized by the use of 12 -layer MLI blankets (outer surface $a / \in$ of $0.49 / 0.71$ ). For the cryogenic Modules $(1,2,4)$, to minimize parasitic strut conduction into the cryogen tankage, the structure was maintained at a lowest possible temperature by the use of SSST as the outer layer of the MLI. Unfortunately, this low temperature of the structure 
would also act as a heat sink for the heat dissipated in the Electronics Bays, which if not controlled, could cause the component temperatures to reduce drastically. Consequently, to avoid this situation, the structural longerons of the three cryogenic tank modules were conductively isolated from the Electronics Bay structure by the use of Vespel pads at each interfacing flange. The entire structure was constructed of highly conductive Al which precluded the buildup of high temperature areas in the structure on the "hot" side of the spacecraft. The structure within each Bay was considered as a part of the interior for that Bay, and its thermal control is described later.

Plumbing Trays and Panels. The Plumbing Tray was located just outside the spacecraft structure on the "cold" side of the spacecraft, which allowed the plumbing and wiring penetrations of the $\mathrm{LH}_{2}$ tankage to assume as low a temperature as possible before they entered each of the three $\mathrm{LH}_{2}$ tank MLI blankets. A lower hot end boundary temperature of these conductive paths lowered the parasitic heat leakage. The Plumbing Tray was attached to the spacecraft structure with stainless steel bolts and G-10 fiberglass spacers in an attempt to thermally isolate it from the spacecraft. This Tray was covered with an MLI blanket with a SSST outer layer to act as a radiator, as shown in Fig. 6.

All component panels were MLI covered with individual thermal control outer layers, as shown in Figs. 6 and 7. Plumbing and wiring from all panels proceeded to the Plumbing Tray before penetrating the PVs of the three $\mathrm{LH}_{2}$ tanks. The "hot" side panels also provided solar flux blockage to the Supply Tank. As in the case of the Plumbing Tray, all panels were conductively decoupled from the spacecraft structure using $\mathrm{G}-10$ spacers.

Thermal control heaters were located on the Vent, Vaporizer and Connector Panels, and were budgeted to the Experiment Subsystem. A heater requirements summary is provided in Table 5 for each subsystem and component level details are in Ref. 1 . Heaters were the only active portion of the TCS and would be composed of Kapton film strip heaters, DTCs and temperature sensors. DTCs would provide automatic control of heaters on the basis of sensor temperature, incorporating the following design features: proportional control of heater power, adjustable set point temperatures and heater output power, heater on/full-on temperature difference of $2^{\circ} \mathrm{F}$ and ground commandable override capability.

Solar Arrays. Minimization of operational solar array temperatures was achieved passively. Although the back of the solar array received no direct solar flux, it did receive large levels of reflected solar radiation from other spacecraft surfaces, and was finished with a high $\in$ Chemglaze Z-202 white paint $\mid a / \epsilon$ $0.2 / 0.89)$ to maximize heat rejection. Measured optical properties $(a / \in 0.73 / 0.86)$ were obtained from the vendor for the Solarex boron silicate cesium solar cells selected. Each solar array hinge/damper would require a low wattage, thermostatically controlled, ground-enabled heater power approximately 30 
minutes prior to array deployment. The array booms were covered with an MLI blanket and finished with low- $\in$ tape on anti-sun sides and low- $a$, high $\in$ tape on the sun-facing sides to minimize boom distortion.

Antenna. Distortion of the HGA and its support boom was minimized passively by the use of MLI blankets on the boom, Al foil $(\alpha / \in 0.35 / 0.55)$ on the dish sun-facing side and Chemglaze Z-202 $(a / \in 0.2 / 0.89)$ white paint on the dish anti-sun side. The HGA motor was MLI covered and had a redundant, thermistor controlled make-up heater. The HGA boom and its deployment hinge/damper had a treatment similar to the solar array boom. The LGAs were conductively coupled to the EB1 panels which were, therefore, maintained in the $30-125^{\circ} \mathrm{F}$ range. The HGA Al foil would not be electrically grounded to the spacecraft since that could cause deterioration of the RF performance. The MLI covering on the booms would minimize relative deflection and the Al foil would minimize focused solar reflection.

Components. The $\mathrm{N}_{2} \mathrm{H}_{4}$ Thruster Modules were conductively coupled to the EB1 side panels, would have MLI blankets and require heaters for the thruster valves and the catalyze beds, as shown in Fig. 15. These heaters would provide temperatures of $40^{\circ} \mathrm{F}$ or higher at ignition and would be maintained by ground commandable, redundant DTC control. Propellant lines were partially wrapped in low- $\in$ tape (75\% tape, $25 \%$ black) and would have heaters. The Propellant Distribution Assembly would have a 12 -layer MLI covering $(a / \in 0.41 / 0.50)$ and would have thermostatically controlled heaters. The gimballed thruster was conductively coupled to the $\mathrm{N}_{2} \mathrm{H}_{4}$ tank support plate which was located inside the EB1.

The sun sensor optics, which protruded the MLI blanket of the EB1, were an integral part of the sensor electronics. Therefore, no separate thermal control of the optics was required. The horizon sensor optics would be MLI covered where the optical head protrudes the EB2 mounting panel. A slit would be provided in the MLI for the mirror.

\section{INTERIOR TCS DESIGN SELECTED}

Interior thermal control was applied to the internals of the EB1 and EB2 enclosures, and the electronics boxes, attitude control sensors, batteries and propulsion components located within. The internal component layouts and the passive surface finishes are described below:

Electronics Bays. In the EB1, the TT\&C Subsystem components such as the computers, transponders, RF processing box, solid state recorders, command and telemetry units, and sequencers were mounted to the insides of the panels on the eight sides of the enclosure. In addition, there were the Power, ACS and Experiment Subsystem electronics boxes which were similarly mounted. These panels provided an efficient means for spreading and rejecting the high thermal dissipation loads of the electronics components, all of which had a duty cycle of 
$100 \%$. The Propulsion Subsystem $\mathrm{N}_{2} \mathrm{H}_{2}$ tankage were mounted on an $\mathrm{Al}$ honeycomb sandwich plate in the center of the EB1. The EB2 contained additional electronics boxes belonging to the TT\&C, Experiment and ACS.

The interior surfaces of the Bays were painted with a high $\alpha / \in(0.95 / 0.85)$, Chemglaze Z-306 black paint to enhance radiative coupling and thus heat exchange between the boxes, panels, $\mathrm{N}_{2} \mathrm{H}_{4}$ tanks and the support structure (Fig. 3). The boxes, structure, tanks and the plate were also painted black promoting augmented heat rejection to the Bay interior. To enhance conductive coupling from the base of each box to the OSR radiators on the outer surface of the panels, silicone boron nitride Chotherm 1671 was used as a 0.125 inch thick thermally conductive interface mounting sheet under each box. The tank support plate was conductively isolated from the side panels and the tanks themselves were isolated from their support plate. A similar thermal control scheme using high $\in$ black paint was used for the EB2 (Fig. 4).

Chotherm 1671 is a thermally conductive interface material designed for transferring heat from electronics components to heat sinks. It is comprised of a silicone binder with boron nitride as the thermally conductive filler. Unlike mica or beryllium oxide, Chotherm does not require thermal grease. Greaseless application of Chotherm precludes the contamination, cracking, migration or drying out associated with greases. It is available in sheet sizes and meets NASA's outgassing requirements. The advantage of using Chotherm is that it reduces the uncertainties of determining contact conductances between two surfaces for use in the thermal analysis models.

There were no survival or back-up heaters provided for the electronics boxes in EB1 since, it had been calculated that in case of loss of power and the ensuing loss of dissipation, the thermal mass of the $\mathrm{N}_{2} \mathrm{H}_{4}$ was sufficient to maintain the boxes within the operating temperature range. This range was maintained longer than the capability of the batteries to supply power without recharging. Moreover, since the duty cycle of the EB1 is $100 \%$, the OSRs had been sized by iterative calculations, so that there is no need for make-up heaters, both for the low power case (attitude acquire) and high power case (on-orbit peak).

The temperature of the Propulsion Subsystem's four $\mathrm{N}_{2} \mathrm{H}_{4}$ tanks was maintained above $40^{\circ} \mathrm{F}$ by ground-commanded redundant heaters. The $\mathrm{GHe}$ pressurant bottles were maintained above $40^{\circ} \mathrm{F}$ by DTC controlled heaters with ground commandable override redundant heaters. Temperature differences between inter-connected $\mathrm{N}_{2} \mathrm{H}_{4}$ tanks were maintained within $10^{\circ} \mathrm{F}$ by groundcommandable actuation of back-up heaters as required.

In the EB2, survival heaters were provided in redundant sets for maintenance of acceptable non-operating temperatures for survival above $-5^{\circ} \mathrm{F}$. These heaters would be enabled automatically when electronics would be made non-operational. 
Batteries. The Power Subsystem components requiring the most stringent thermal control were the nickel-cadmium batteries. Each battery dissipated $25 \mathrm{~W}$ during the charge and discharge cycles. Because battery life is inversely related to temperature, a $85^{\circ} \mathrm{F}$ maximum was desirable to ensure adequate operation throughout the duration of the mission. Consequently, each battery was located in two thermal control compartments in EB1, which were isolated from the hotter $\left(125^{\circ} \mathrm{F}\right.$ ) electronics compartment by structural bulkheads (Fig. 16). The compartments were covered with MLI blankets on the inner and outer surfaces, both with a black outer layer $(\alpha / \in 0.85 / 0.85)$. The battery itself was painted black $(a / \in 0.85 / 0.85)$ on all sides. The forward panels of the compartments were covered with OSR radiator to which the batteries were radiatively coupled by the high $\in$ black paint. Battery temperature was maintained above $30^{\circ} \mathrm{F}$ by redundant DTCs and heaters with ground override capability. Information on battery thermal control is obtained from Ref. 4.

The telemetry data and command requirements for the TCS would require 185 channels in the TT\&C Subsystem and are described in Ref. 1. The heater control, location and activation techniques are also provided in Ref. 1 . Spacecraft heaters and associated controllers would be functionally redundant, in cases where heated units themselves are not. Due to the closed-loop nature of DTC operation, uplink anomalies would not preclude nominal operation of heaters; however, grounded commandable override capability would be provided. Certain heaters would be controlled by ground command only for components associated with ground-commanded events (e.g. solar array deployment and RCS thruster firings).

\section{SELECTED TCS PERFORMANCE PREDICTIONS}

As explained above, four on-orbit thermal cases for the selected spacecraft attitude were analyzed and shown in Fig. 13:

1. Operational on-orbit cold case with $\beta=0^{\circ}$

2. Operational on-orbit hot case with $\beta=41^{\circ}$

3. On-orbit load shedding case with $\beta=0^{\circ}$

4. On-orbit loss of attitude case with $\beta=0^{\circ}$

Predicted temperature results of on-orbit thermal analysis for all subsystems and components are presented in detail in Ref. 1 and compared to the required operational temperature ranges. A summary of results is presented in Table 3. Where the predicted minimum temperature fell below the operational minimum, heaters were sized to maintain temperature. The minimum temperature was calculated for the worst on-orbit cold environmental conditions of $\beta=0^{\circ}$ with the lowest power dissipation from the attitude acquire power profile. The maximum temperature was calculated for the worst hot case of $\beta=41^{\circ}$ and with the maximum on-orbit peak power dissipation.

Of specific interest were the temperature ranges of the Supply Tank purge 
diaphragm outer surface and the Plumbing Tray, which have previously been presented graphically in Figs. 9 and 11, respectively, for the cold and hot cases. For minimizing the heat leak through the MLI blanket, the outer layer of the purge diaphragm required a thermal control surface with the optimum $a / \in$ thermo-optical properties. For cryogenic tankage on board spacecraft, the goal is to reduce the $a$ while maximizing $\in$, thereby reducing solar flux absorption and maximizing radiation to space for the outer surface. This produces the coldest temperature boundary for the MLI parasitic heat leak.

In the case of the COLD-SAT Supply Tank, three different materials were considered for the outer layer of the purge diaphragm, namely: aluminized Kapton with an $a / \in$ of $0.49 / 0.71$, Beta cloth with an $\alpha / \in$ of $0.22 / 0.90$ and a SSST with an $\alpha / \in$ of $0.09 / 0.75$. White paint was not considered as an outer surface coating due to the requirement that this diaphragm be flexible, thereby precluding painted coatings.

Analysis results for the three cases are provided in Fig. 17 for the purge diaphragm where the surface temperature is plotted versus time. It can be seen that the SSST produced the lowest temperature profile with the aluminized Kapton being the warmest. On orbit, when the sun was impinging on the purge diaphragm, the average surface temperature range was from a minimum of $-25^{\circ} \mathrm{F}$ for the SSST to a maximum of $+25^{\circ} \mathrm{F}$ for the Kapton. Since the goal was to design the coldest purge diaphragm outer surface, the SSST was the material that was selected for the Supply Tank. The effects of varying the $a / \in$ properties of the purge diaphragm outer surface on the total heat flux on the PV are presented in Fig. 18. As the $a / \in$ increased, the temperature of the purge diaphragm increased. Being the thermal boundary for the heat leakage through the MLI, a higher diaphragm temperature produced a higher flux. For the materials considered for the purge diaphragm, the total heat flux varied from $0.0638 \mathrm{Btu} / \mathrm{hr}^{-\mathrm{ft}^{2}}$ for the lowest case to the highest of 0.0764 producing an increase of $20 \%$. However, all materials produced fluxes which were within the required goal of $0.1 \mathrm{Btu} / \mathrm{hr}-\mathrm{ft} 2$. Further discussion can be obtained in Ref. 3.

Temperature histories for the Propulsion Subsystem $\mathrm{N}_{2} \mathrm{H}_{4}$ tanks are plotted in Fig. 19, for both the hot and cold cases. Temperatures for both cases are within the required range. The goal of intra-tank temperature difference to be less than $10^{\circ}$ was achieved. For the case of load shedding with no power dissipation in EB1 where the $\mathrm{N}_{2} \mathrm{H}_{4}$ tanks are located, it can be seen by extrapolating Fig. 20 that it will take 35 hours for the $\mathrm{N}_{2} \mathrm{H}_{4}$ to freeze at $34.8^{\circ} \mathrm{F}$ starting from the initial temperature of $75^{\circ} \mathrm{F}$. This case was analyzed for a worst case condition of $\beta=$ $0^{\circ}$ attitude with zero power dissipation in EB1. As seen in Figs. 21 and 22, the thermal control system for the batteries maintains the temperature within acceptable range for both the nominal hot and cold cases, and also the loss of attitude case. The loss of attitude control case was considered when the spacecraft long axis is perpendicular to the orbit plane and solar flux is incident on the EB1 Battery No. 2 panel with maximum power dissipation from the rest of the 
electronics.

COLD-SAT heater power requirements have been summarized in Table 5. Make-up heaters are those that are necessary to maintain a component within operating range when the component is in normal operating mode and dissipating power. Back-up heaters are required to maintain the component within operating temperature range when the component is non-operating. Survival heaters are needed for maintaining a cold start turn-on temperature of $-5^{\circ} \mathrm{F}$ for electronic components when these are shut down. Heaters are not required for the EB1 components except for the batteries and the Propulsion Subsystem components. This is due to the warm environment maintained in the EB1 by the large thermal mass of the $\mathrm{N}_{2} \mathrm{H}_{4}$ tanks even when there is a sudden disruption of electrical power dissipation. This situation may arise when there is a loss of spacecraft attitude resulting in zero power generation from the solar arrays. For the four hours that the batteries can supply power without recharging, the temperature of the EB1 electronics boxes stay within operating range due to the $N_{2} \mathrm{H}_{4}$ tanks. Fig. 23 shows predicted solar array transient temperature responses for $\beta=0^{\circ}$ and $\beta=$ $41^{\circ}$ cases.

\section{CONCLUSION}

The COLD-SAT spacecraft Thermal Control Subsystem is a passive design and uses heaters for augmenting the passive thermal control. The analysis that has been performed on the design has verified that all critical design goals have been met. Individual component temperatures are within specified limits for the duration of the entire mission.

\section{REFERENCES}

1. Kramer, E. H., Editor, "Conceptual Design of the COLD-SAT Spacecraft," NASA TM, to be published.

2. Arif, H., "Spacecraft Attitude Impacts on COLD-SAT Non-Vacuum Jacketed $\mathrm{LH}_{2}$ Supply Tank Thermal Performance, "AIAA Paper 90-1672, AIAA/ASME 5th Joint Thermophysics and Heat Transfer Conference, Seattle, Washington, June 1990.

3. Arif, H., "Thermal Aspects of Design for the COLD-SAT Non-Jacketed Supply Tank Concept," AIAA Paper 90-2059, 26th AIAA/SAE/ASME/ASEE Joint Propulsion Conference and Exhibit, Orlando, Florida, July 1990.

4. Konzok, H.-G, et al., "Battery Thermal Design and Performance in European Geo-Satellite Programs, "SAE 871484, 17th Intersociety Conference on Environmental Systems, Seattle, Washington, July 13-15, 1987. 
TABLE 1. SUPPLY TANK STRUCTURE AND PLUMBING TRAY TEMPERATURE, ${ }^{\circ} \mathrm{F}$

\begin{tabular}{|l|c|c|c|c|}
\hline \multirow{2}{*}{ COMPONENT } & \multicolumn{2}{|c|}{ ATTITUDE A } & \multicolumn{2}{c|}{ ATTITUDE B } \\
\cline { 2 - 5 } & $\beta-0^{\circ}$ & $\beta=41^{\circ}$ & $\beta=41^{\circ}$ & $\beta=0^{\circ}$ \\
\hline $\begin{array}{l}\text { LONGERONS } \\
\text { (AVERAGE OF 8) }\end{array}$ & -102 & -44 & -28 & -8 \\
\hline PLUMBING TRAY & -102 & -98 & -87 & -71 \\
\hline
\end{tabular}

TABLE 2. SUBSYSTEM POWER DISSIPATIONS,

\begin{tabular}{|l|c|c|}
\multicolumn{3}{c|}{ W } \\
\hline SUBSYSTEM & $\begin{array}{c}\text { ATTITUDE } \\
\text { ACQUIRE }\end{array}$ & $\begin{array}{c}\text { ON-ORBIT } \\
\text { PEAK }\end{array}$ \\
\hline TT\&C & 309 & 371 \\
EXPERIMENT & 45 & 100 \\
ACS & 73 & 73 \\
POWER & 120 & 130 \\
\hline \multicolumn{1}{|r|}{ TOTAL } & 547 & 674 \\
\hline
\end{tabular}


TABLE 3. DESIGN AND PREDICTED TEMPERATURE RANGES, ${ }^{\circ} \mathrm{F}$

\begin{tabular}{|c|c|c|c|c|c|c|c|c|}
\hline \multirow{2}{*}{$\begin{array}{l}\text { SUBSYSTEM } \\
\text { COMPONENT'S }\end{array}$} & \multicolumn{2}{|c|}{ OPERATIONAL } & \multicolumn{2}{|c|}{ NON-OPERATIONAL } & \multicolumn{4}{|c|}{ PREDICTED } \\
\hline & MIN & MAX & MIN & $\operatorname{MAX}$ & $\underset{(\beta=0)}{\operatorname{MIN}}$ & $\begin{array}{c}W / \\
\text { HEATER }\end{array}$ & $\operatorname{MAX}_{(\beta=41)}$ & $\begin{array}{c}W / \\
\text { HEATER }\end{array}$ \\
\hline $\begin{array}{l}\text { ITIC SUBSYSTEM } \\
\text { COMPUTERS } \\
\text { TRANSPONDERS } \\
\text { RF PROCESSING BOX } \\
\text { SOLID STATE RECORDERS } \\
\text { RMT CMD/TLM UNITS, CTUS } \\
\text { SEQUENCERS } \\
\text { HGA ELECTRONICS/MOTOR } \\
\text { LGAS } \\
\text { REDUNDANCY CONTROL UNIT } \\
\text { COMMAND RECEIVER }\end{array}$ & $\begin{array}{l}30 \\
30 \\
30 \\
30 \\
30 \\
30 \\
30 \\
30 \\
30 \\
30\end{array}$ & $\begin{array}{l}125 \\
125 \\
125 \\
125 \\
125 \\
125 \\
125 \\
125 \\
125 \\
125\end{array}$ & $\begin{array}{l}-5 \\
-5 \\
-5 \\
-5 \\
-5 \\
-5 \\
-5 \\
-5 \\
-5 \\
-5\end{array}$ & $\begin{array}{l}145 \\
145 \\
145 \\
145 \\
145 \\
145 \\
145 \\
145 \\
145 \\
145\end{array}$ & $\begin{array}{l}51 \\
51 \\
60 \\
59 \\
57 \\
59 \\
50 \\
51 \\
58 \\
51\end{array}$ & & $\begin{array}{l}92 \\
92 \\
90 \\
90 \\
90 \\
90 \\
79 \\
92 \\
85 \\
92\end{array}$ & \\
\hline $\begin{array}{l}\text { EXPERIMENT SUBSYSTEM } \\
\text { GHe BOTTLES } \\
\text { GH2 BOTTLES } \\
\text { T-0 PANEL } \\
\text { VAPORIZER PANELS } \\
\text { HELIUM PANELS } \\
\text { VENT PANELS } \\
\text { PLUMBING TRAY } \\
\text { CONNECTOR PANELS } \\
\text { SUPPLY TANK OUTER } \\
\text { SURFACE } \\
\text { EXP. DATA UNITS } \\
\text { CONDITIONERS } \\
\text { DATA ACQ. UNITS } \\
\text { MOTOR INVERTERS }\end{array}$ & $\begin{array}{r}-65 \\
-423 \\
-423 \\
40 \\
-40 \\
0 \\
-423 \\
0 \\
-200 \\
30 \\
30 \\
30 \\
30\end{array}$ & $\begin{array}{r}200 \\
70 \\
-100 \\
150 \\
150 \\
150 \\
-100 \\
100 \\
0 \\
125 \\
125 \\
125 \\
125\end{array}$ & $\begin{array}{r}-320 \\
-423 \\
-423 \\
-40 \\
-100 \\
-100 \\
-423 \\
-100 \\
-300 \\
-5 \\
-5 \\
-5 \\
-5\end{array}$ & $\begin{array}{l}200 \\
200 \\
150 \\
150 \\
150 \\
150 \\
150 \\
150 \\
300 \\
\\
145 \\
145 \\
145 \\
145\end{array}$ & $\begin{array}{r}-53 \\
-52 \\
-96 \\
-88 \\
-36 \\
-82 \\
-102 \\
-74 \\
-115 \\
67 \\
58 \\
50 \\
52\end{array}$ & $\begin{array}{r}40 \\
0\end{array}$ & $\begin{array}{r}-54 \\
26 \\
-84 \\
93 \\
2 \\
107 \\
-98 \\
125 \\
-75 \\
\\
103 \\
85 \\
92 \\
93\end{array}$ & \\
\hline \multirow{2}{*}{$\begin{array}{l}\text { SUBSYSTEM/ } \\
\text { COMPONENTS }\end{array}$} & \multicolumn{2}{|c|}{ OPERATIONAL } & \multicolumn{2}{|c|}{ NON-OPERATIONAL } & \multicolumn{4}{|c|}{ PREDICTED } \\
\hline & MIN & MAX & MIN & MAX & $\stackrel{\operatorname{MIN}}{(\beta=0)}$ & $\begin{array}{c}W / \\
\text { HEATER }\end{array}$ & $\underset{(\beta=41)}{\operatorname{MAX}}$ & $\begin{array}{c}W / \\
\text { HEATER }\end{array}$ \\
\hline $\begin{array}{l}\text { PROPULSION SUBSYSTEM } \\
\text { PROP. DISTRIBUTION ASSY } \\
\text { GHE BOTTLES } \\
\text { N2H4 TANKS } \\
\text { ROCKET ENGINE MODULES }\end{array}$ & $\begin{array}{l}40 \\
40 \\
40 \\
40\end{array}$ & $\begin{array}{l}120 \\
120 \\
120 \\
120\end{array}$ & $\begin{array}{l}40 \\
40 \\
40 \\
40\end{array}$ & $\begin{array}{l}120 \\
120 \\
120 \\
120\end{array}$ & $\begin{array}{r}-57 \\
-74 \\
57 \\
73\end{array}$ & $\begin{array}{l}60 \\
60\end{array}$ & $\begin{array}{r}-35 \\
-62 \\
85 \\
101\end{array}$ & $\begin{array}{l}60 \\
60\end{array}$ \\
\hline $\begin{array}{l}\text { AC SUBSYSTEM } \\
\text { INERTIAL REF. UNIT } \\
\text { HORIZON SENSOR ELECS. } \\
\text { FINE SUN SEN. ELECS. } \\
\text { MAGNETOMETERS } \\
\text { ACS INTERACE ELECS. } \\
\text { HORIZON SENSORS OPTICS } \\
\text { FINE SUN SEN. OPTICS }\end{array}$ & $\begin{array}{l}30 \\
30 \\
15 \\
30 \\
30 \\
-5 \\
15\end{array}$ & $\begin{array}{l}105 \\
125 \\
125 \\
125 \\
125 \\
140 \\
140\end{array}$ & $\begin{array}{r}-65 \\
-5 \\
-40 \\
-5 \\
-5 \\
-5 \\
-40\end{array}$ & $\begin{array}{l}165 \\
140 \\
160 \\
145 \\
145 \\
140 \\
160\end{array}$ & $\begin{array}{l}60 \\
57 \\
48 \\
49 \\
52 \\
47 \\
73\end{array}$ & - & $\begin{array}{r}90 \\
88 \\
79 \\
79 \\
93 \\
90 \\
101\end{array}$ & \\
\hline $\begin{array}{l}\text { POWER SUBSYSTEM } \\
\text { BATTERIES } \\
\text { SOLAR ARRAYS } \\
\text { POWER CONTROL UNIT } \\
\text { POWER DIST. UNIT } \\
\text { PYRO CONTROL BOX }\end{array}$ & $\begin{array}{r}30 \\
-95 \\
30 \\
30 \\
30\end{array}$ & $\begin{array}{r}85 \\
160 \\
125 \\
125 \\
125\end{array}$ & $\begin{array}{r}30 \\
-95 \\
-5 \\
-5 \\
-5\end{array}$ & $\begin{array}{r}85 \\
160 \\
145 \\
145 \\
145\end{array}$ & $\begin{array}{r}48 \\
-70 \\
61 \\
57 \\
60\end{array}$ & & $\begin{array}{r}79 \\
135 \\
88 \\
79 \\
88\end{array}$ & \\
\hline $\begin{array}{l}\text { STRUCTURAL SUBSYSTEM } \\
\text { ELECT. BAY PANELS } \\
\text { STRUTS } \\
\text { SUPPLY TANK SUPPORT STR. } \\
\text { N2H4 TANK PLATE }\end{array}$ & $\begin{array}{r}30 \\
-100 \\
-150 \\
40\end{array}$ & $\begin{array}{r}125 \\
50 \\
50 \\
120\end{array}$ & $\begin{array}{r}-5 \\
-100 \\
-150 \\
40\end{array}$ & $\begin{array}{r}145 \\
50 \\
50 \\
120\end{array}$ & $\begin{array}{r}47 \\
-65 \\
-110 \\
58\end{array}$ & & $\begin{array}{r}103 \\
-5 \\
-44 \\
85\end{array}$ & \\
\hline
\end{tabular}


TABLE 4. RADIATOR SURFACE AREA REQUIREMENTS

\begin{tabular}{|l|c|c|c|c|}
\hline \multicolumn{1}{|c|}{ PANEL } & $\begin{array}{c}\text { LOW/HI } \\
\text { DISSIPATION, } W\end{array}$ & RADIATOR TYPE & $\alpha / \epsilon$ & DIMENSIONS, IN. \\
\hline EB \#1 NORTH & $28 / 28$ & OSR & $0.1 / 0.79 \mathrm{BOL}$ & $10.0 \times 16.0$ \\
EB \#1 SOUTH & $28 / 46$ & OSR & $0.1 / 0.79 \mathrm{BOL}$ & $10.0 \times 16.0$ \\
EB \#1 EAST & $31 / 31$ & OSR & $0.1 / 0.79 \mathrm{BOL}$ & $8.75 \times 12.0$ \\
EB \#1 WEST & $31 / 31$ & OSR & $0.1 / 0.79 \mathrm{BOL}$ & $6.75 \times 12.0$ \\
EB \#1 NORTH EAST & $58 / 117$ & OSR & $0.1 / 0.79 \mathrm{BOL}$ & $14.75 \times 24.5$ \\
EB \#1 NORTH WEST & $35 / 45$ & OSR & $0.1 / 0.79 \mathrm{BOL}$ & $16.75 \times 22.5$ \\
EB \#1 SOUTH EAST & $66 / 81$ & OSR & $0.1 / 0.79 \mathrm{BOL}$ & $18.75 \times 26.5$ \\
EB \#1 SOUTH WEST & $77 / 77$ & OSR & $0.1 / 0.79 \mathrm{BOL}$ & $9.75 \times 13.25$ \\
EB \#1 FWD/BATT 1 & SEE EB \#1 NORTH & OSR & $0.1 / 0.79 \mathrm{BOL}$ & $16.0 \times 10.0$ \\
EB \#1 FWD/BATT 2 & SEE EB \#1 SOUTH & OSR & $0.1 / 0.79 \mathrm{BOL}$ & $16.0 \times 10.0$ \\
EB \#2 NORTH & $3 / 3$ & OSR & $0.1 / 0.79 \mathrm{BOL}$ & $2.0 \times 2.0$ \\
EB \#2 SOUTH & $3 / 3$ & OSR & $0.1 / 0.79 \mathrm{BOL}$ & $2.0 \times 2.0$ \\
EB \#2 EAST & $70 / 70$ & OSR & $0.1 / 0.79 \mathrm{BOL}$ & $18.0 \times 20.0$ \\
EB \#2 WEST & $45 / 55$ & OSR & $0.1 / 0.79 \mathrm{BOL}$ & $10.0 \times 12.0$ \\
EB \#2 NORTH EAST & $2 / 2$ & OSR & $0.1 / 0.79 \mathrm{BOL}$ & $1.0 \times 1.5$ \\
EB \#2 NORTH WEST & $20 / 35$ & OSR & $0.1 / 0.79 \mathrm{BOL}$ & $10.0 \times 12.0$ \\
EB \#2 SOUTH EAST & $50 / 50$ & OSR & $0.1 / 0.79 \mathrm{BOL}$ & $14.0 \times 16.0$ \\
EB \#2 SOUTH WEST & $0 / 0$ & & & $\cdots$ \\
\hline
\end{tabular}


TABLE 5. HEATER REQUIREMENTS SUMMARY

\begin{tabular}{|c|c|c|}
\hline SUBSYSTEM & HEATER TYPE & POWER REQUIREMENTS, \\
\hline PROPULSION & MAKE-UP & 30 \\
& BACK-UP $^{2}$ & 60 \\
SORVIVAL & 25 \\
POWER & MAKE-UP & 0 \\
& BACK-UP & 40 \\
TT\&C & SURVIVAL & 27.5 \\
& MAKE-UP & 5 \\
& BACK-UP & 0 \\
ACS & SURVIVAL & 8 \\
& MAKE-UP & 0 \\
& BACK-UP & 0 \\
EXPERIMENT & SURVIVAL & 10 \\
& MAKE-UP & 30 \\
& BACK-UP & 0 \\
& SURVIVAL & 6.5 \\
\hline TOTAL & MAKE-UP & 65 \\
& BACK-UP & 100 \\
& SURVIVAL & 77 \\
\hline
\end{tabular}

1 THERMISTOR CONTROLLED

2 DUAL TEMPERATURE CONTROLLER (DTC) CONTROLLED

3 THERMISTOR CONTROLLED

MAKEUP HEATER DUTY CYCLE 50\% OR LESS 


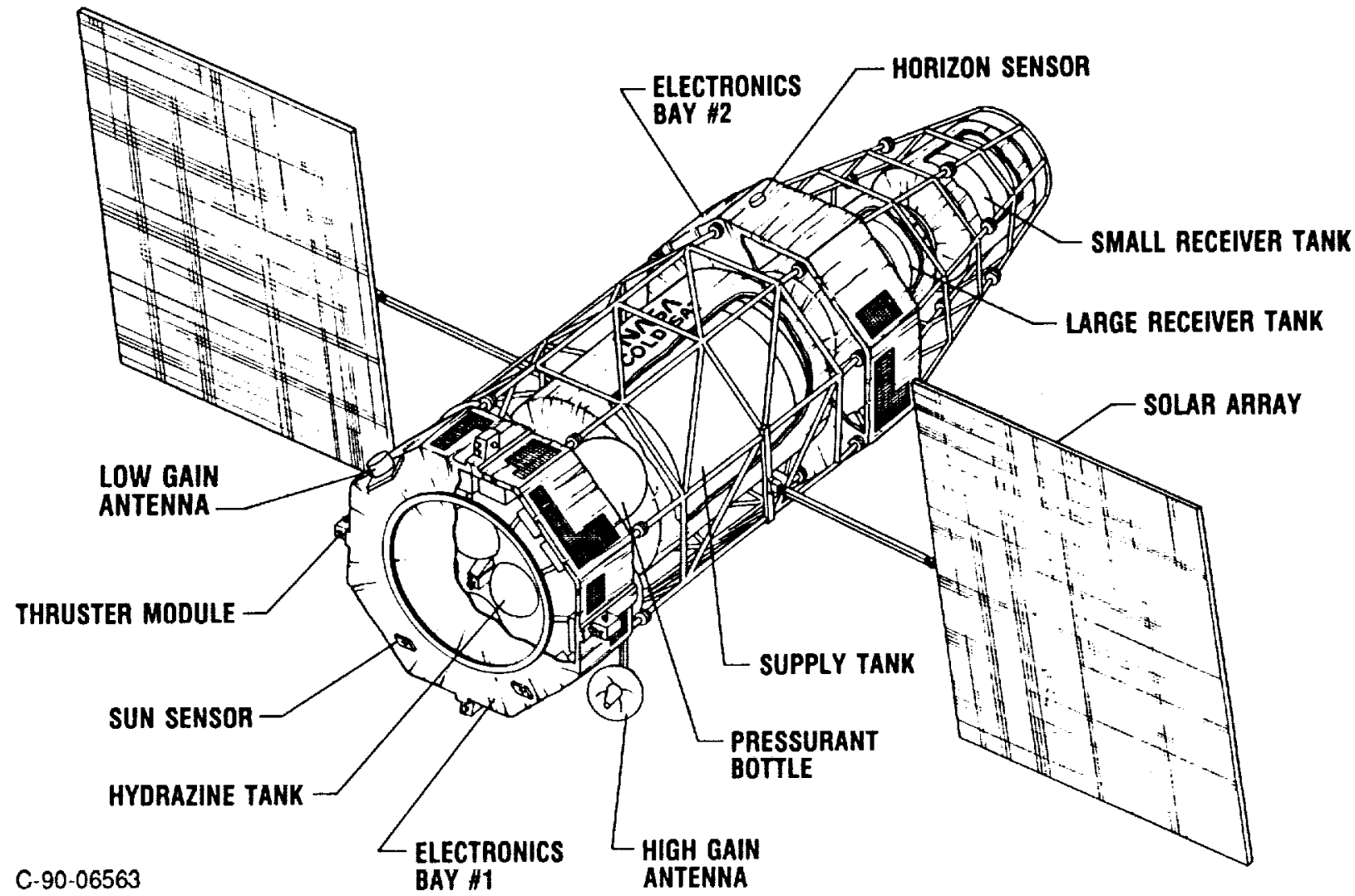

Figure 1.-Cryogenic on-orbit liquid depot-storage, acquisition, transfer (COLD-SAT) spacecraft.
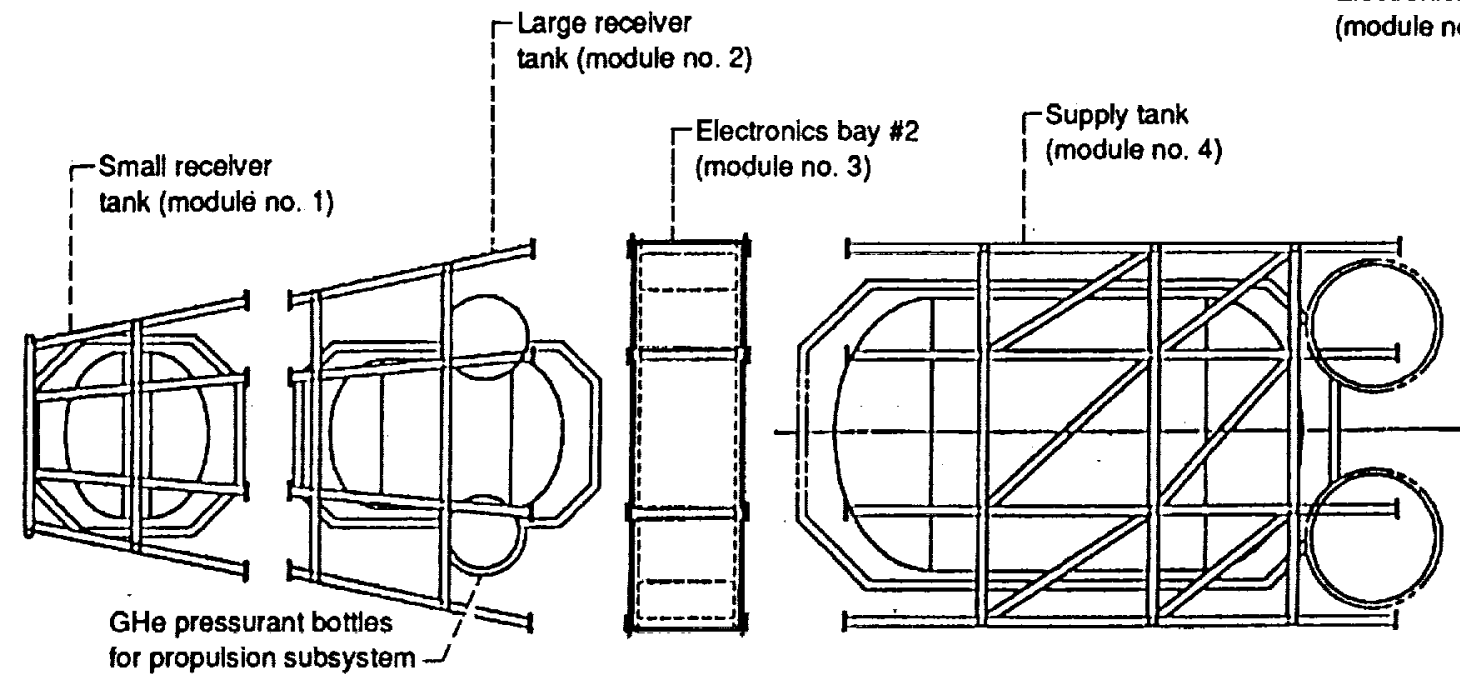

Electronics bay \#1 (module no. 5) for propulsion subsystem -

Figure 2.-Spacecraft modular design. 
Black paint ( $\alpha / \epsilon=0.85 / 0.85)$ on panels, electronic boxes,

hydrazine tanks,

tanks support plate

$$
\text { pport plate }
$$

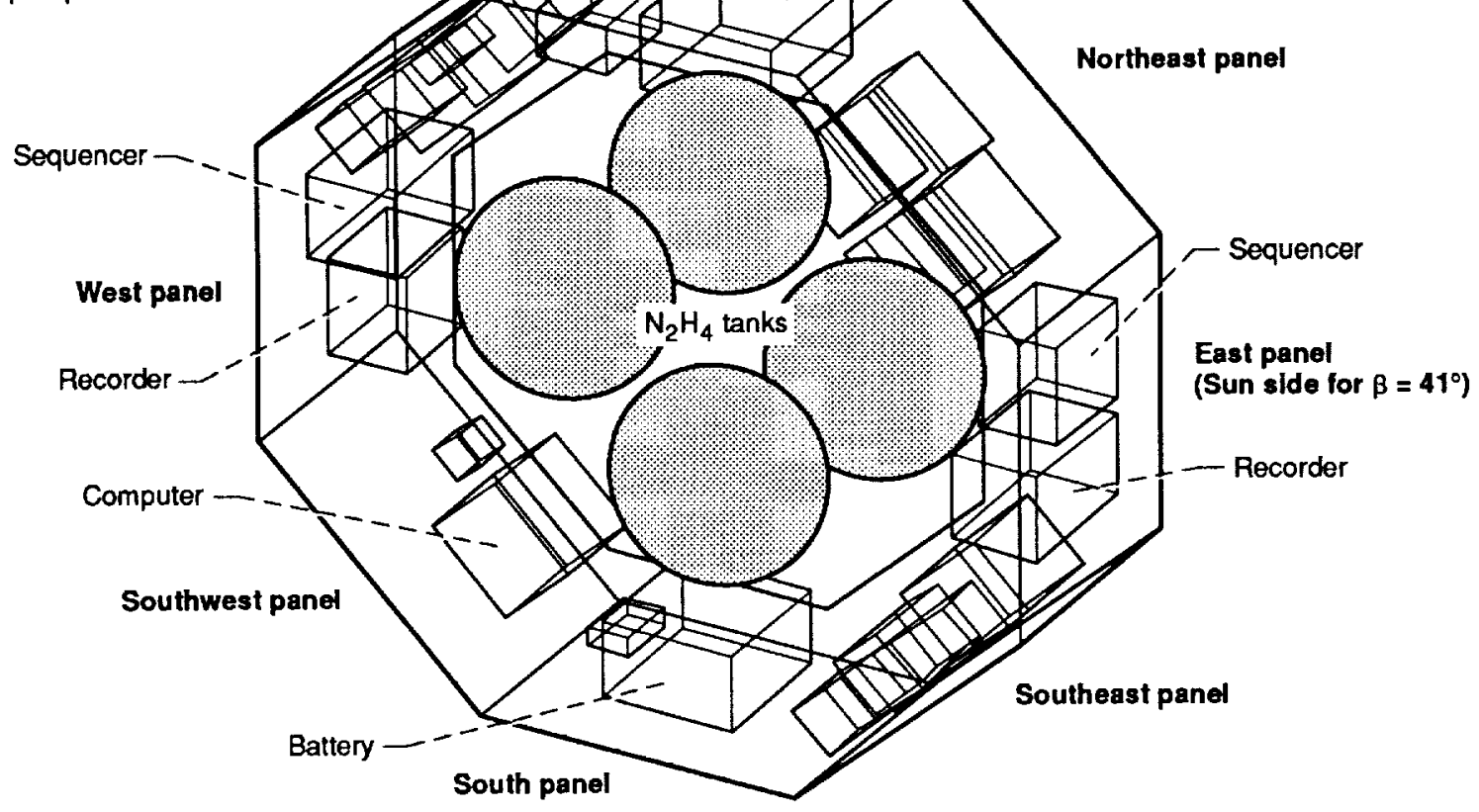

Figure 3.-Electronics bay no. 1 interior.

Black paint $(\alpha / \epsilon=0.85 / 0.85)$ on panels and electronic boxes

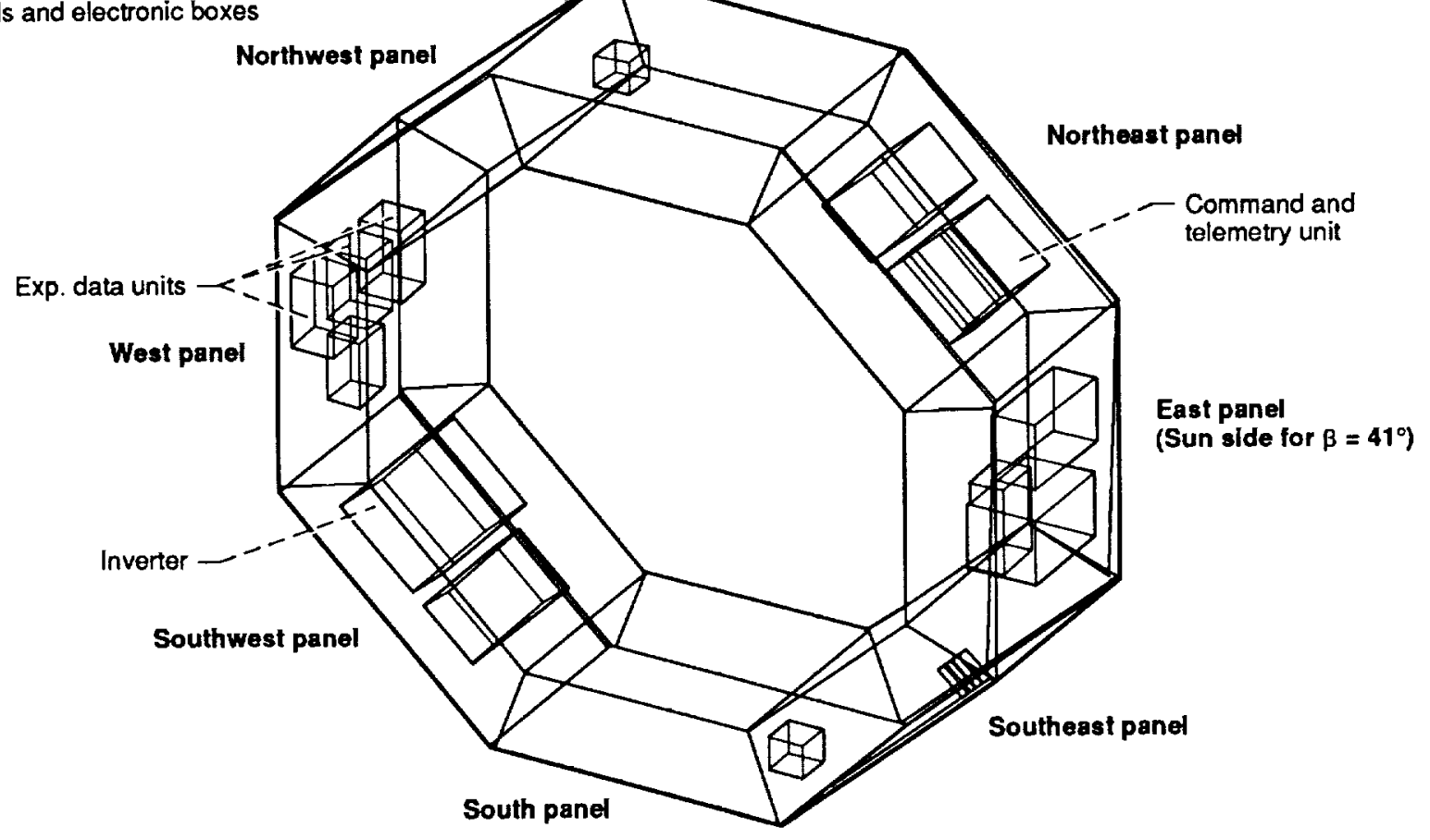

Figure 4.-Electronics bay no. 2 interior. 


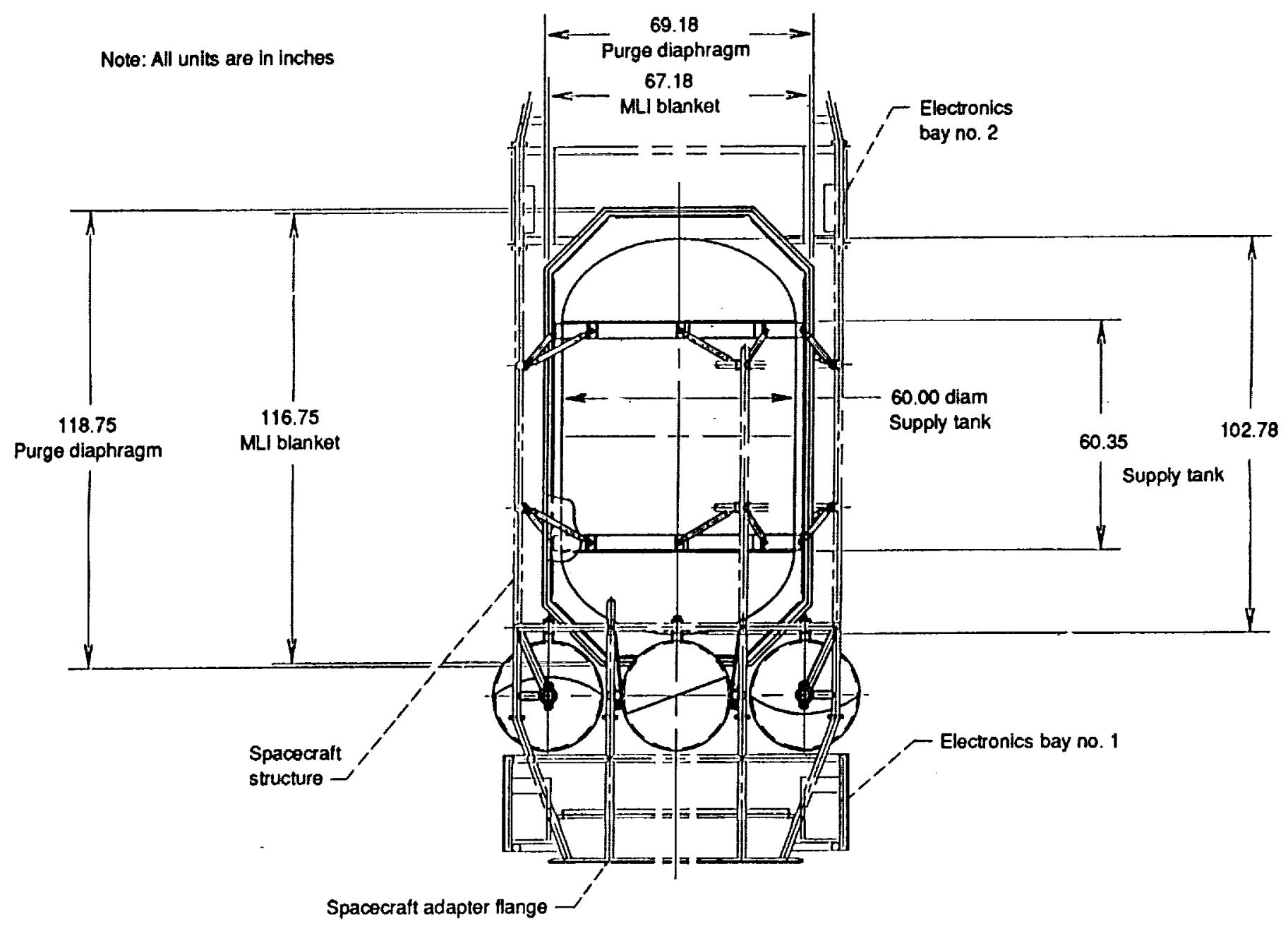

Figure 5.--Supply tank module. 


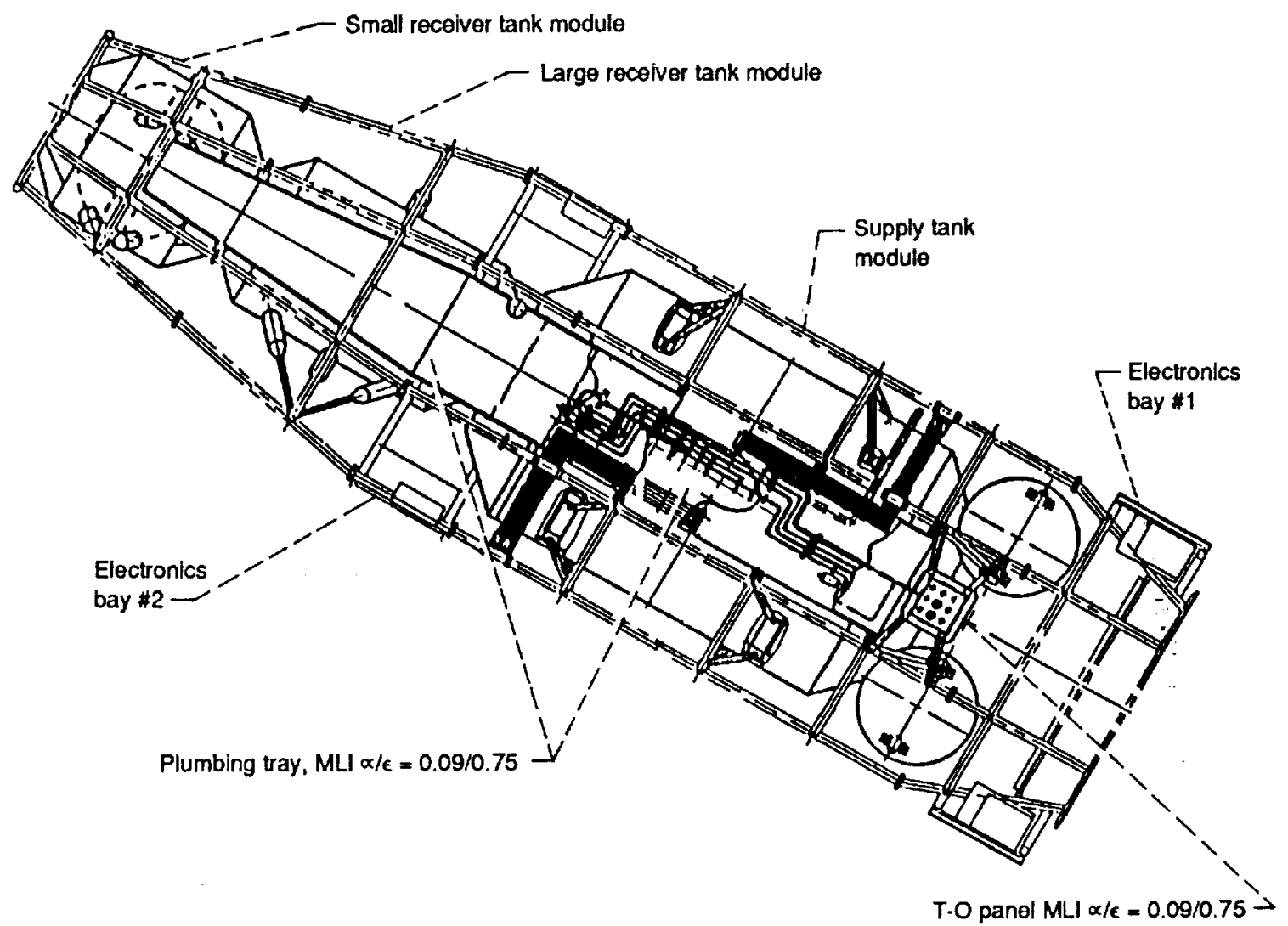

Figure 6.-View of the spacecraft "cold" side showing the plumbing tray. 


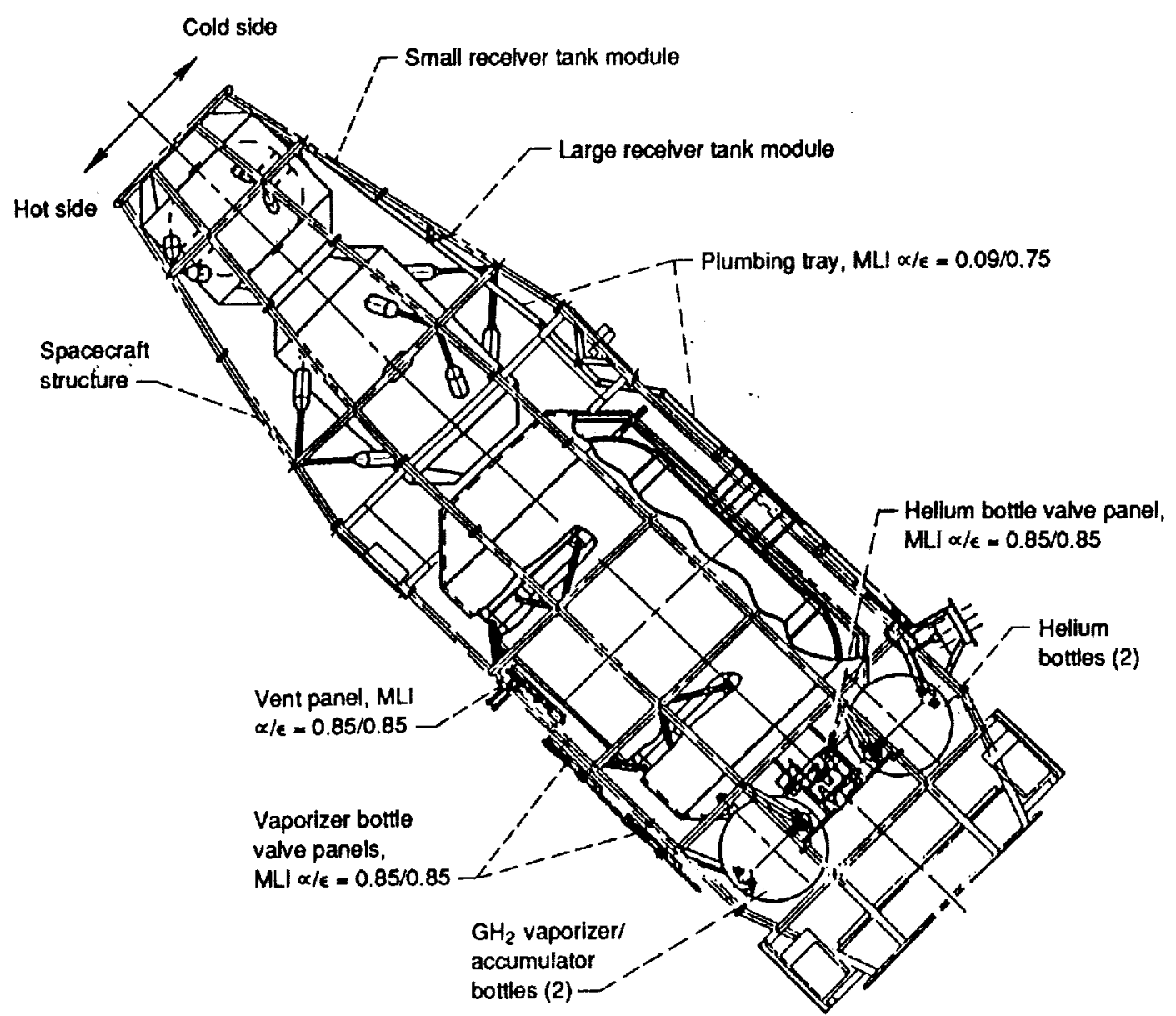

Figure 7.-COLD-SAT thermal bifurcation into "hot" and "cold" sides. 


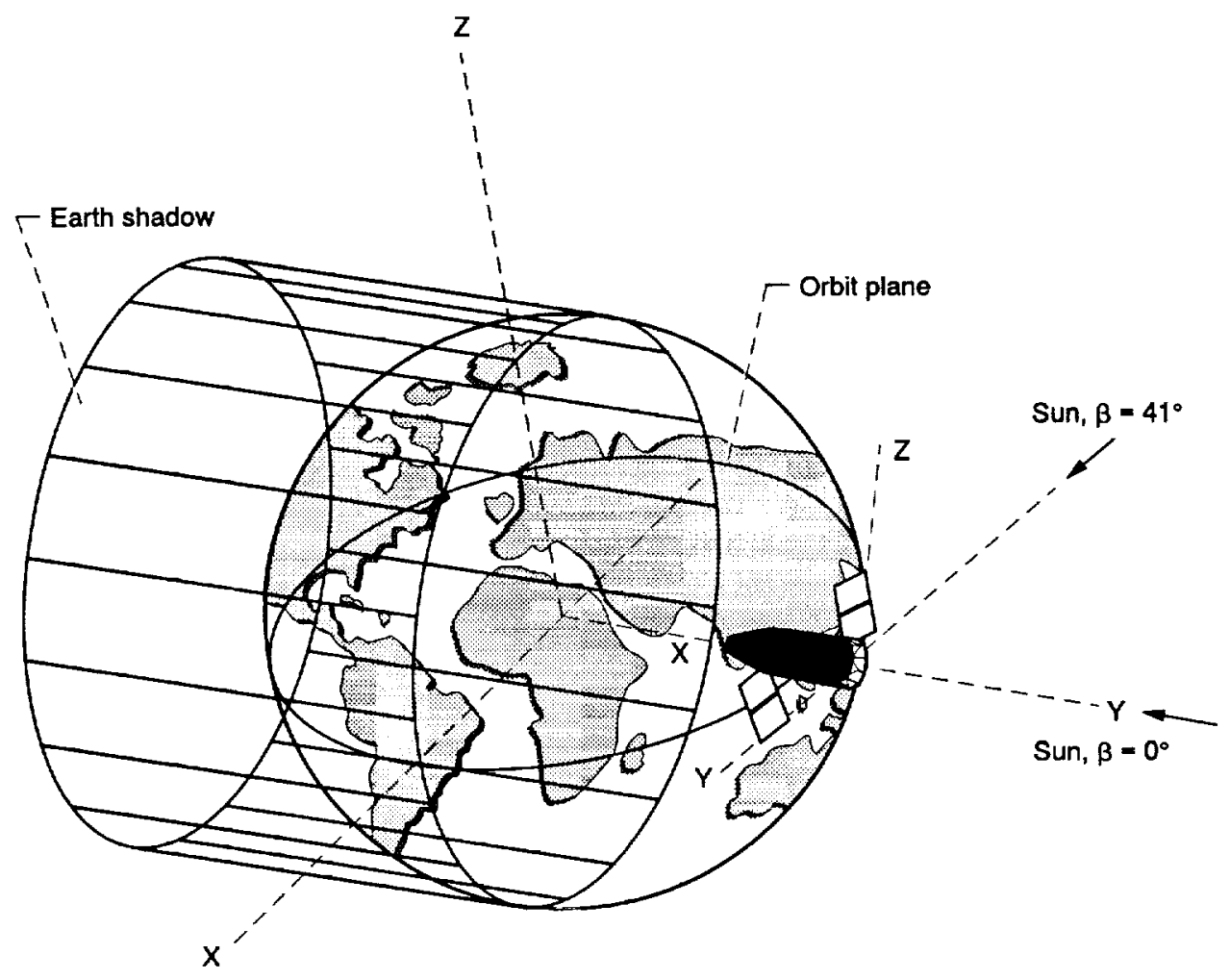

(a) Spacecraft attitude "A".

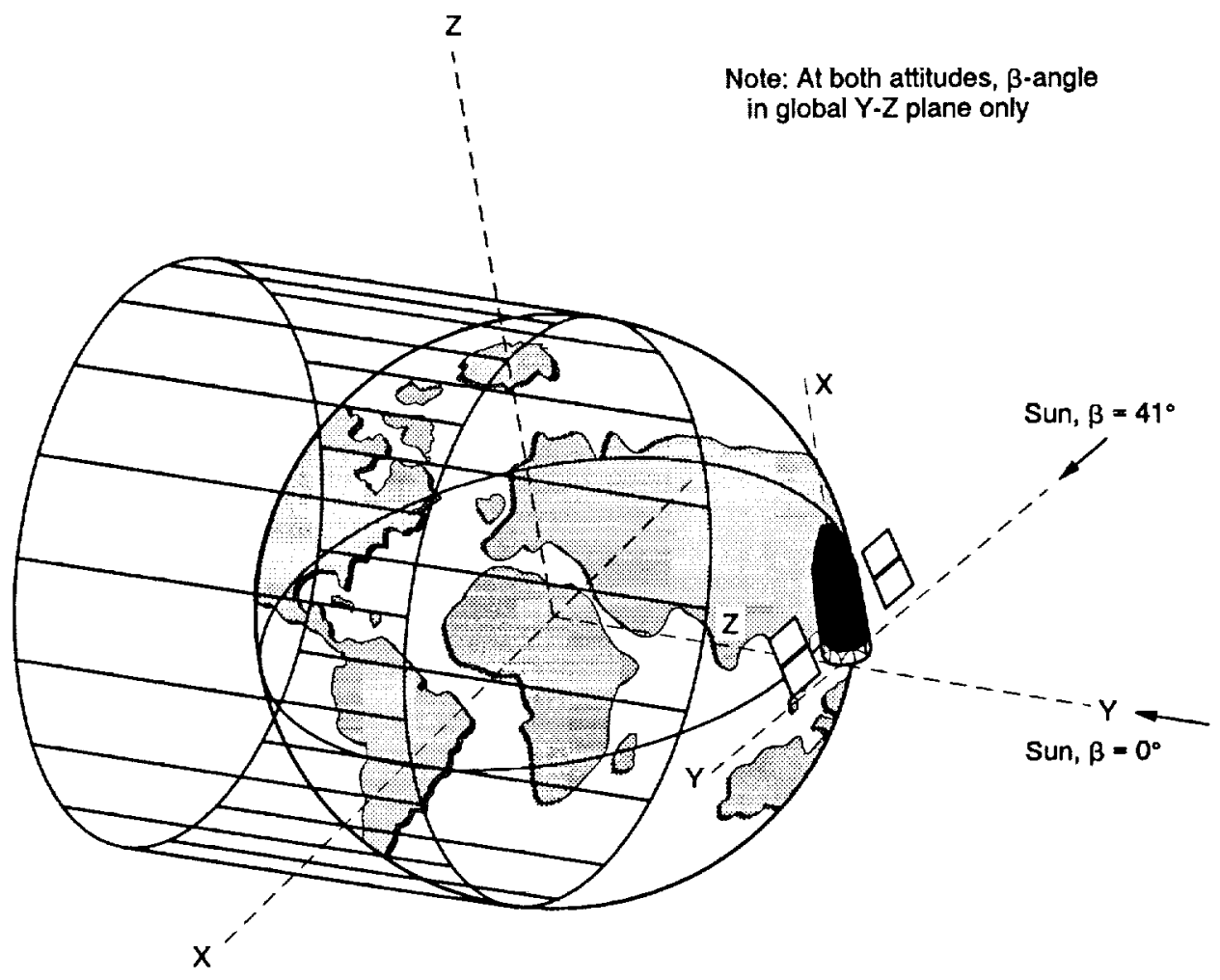

(b) Spacecraft attitude "B".

Figure 8.-COLD-SAT spacecraft attitudes considered. 


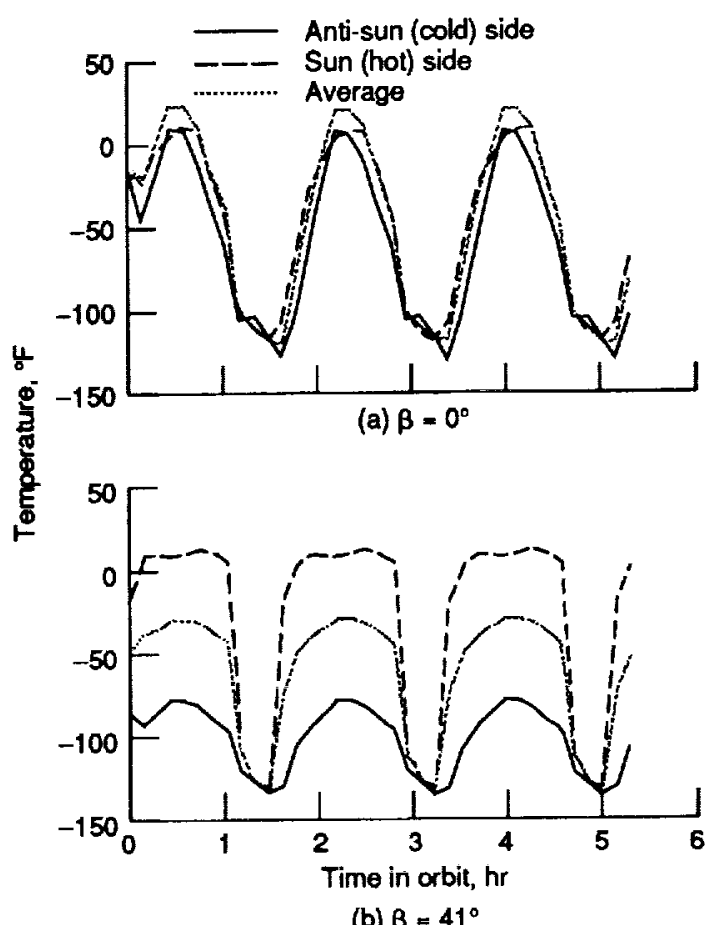

(b) $\beta=41^{\circ}$

Figure 9.-Supply tank purge diaphragm temperature for attitude "A".

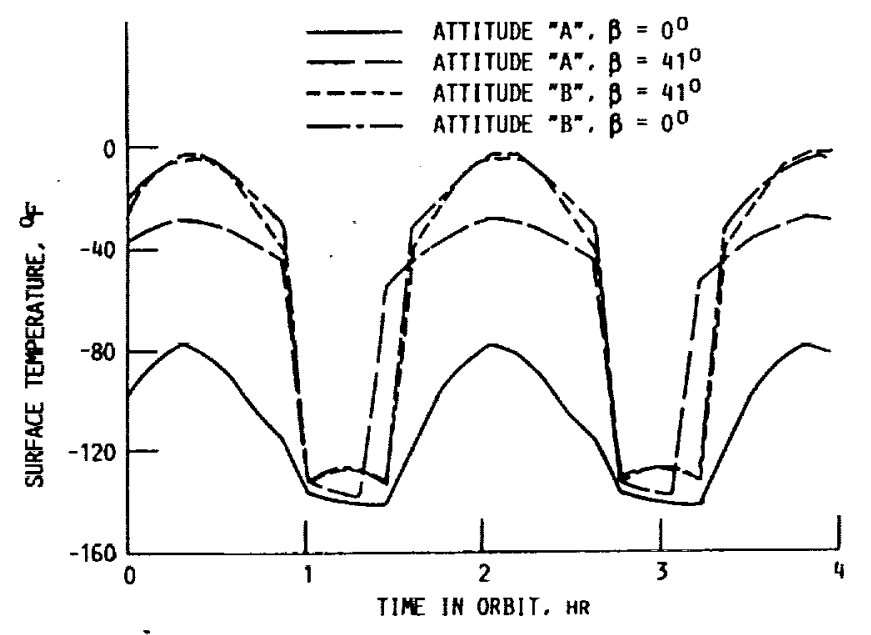

Figure 10.-Purge diaphragm average temperaturespacecraft attifude effects.

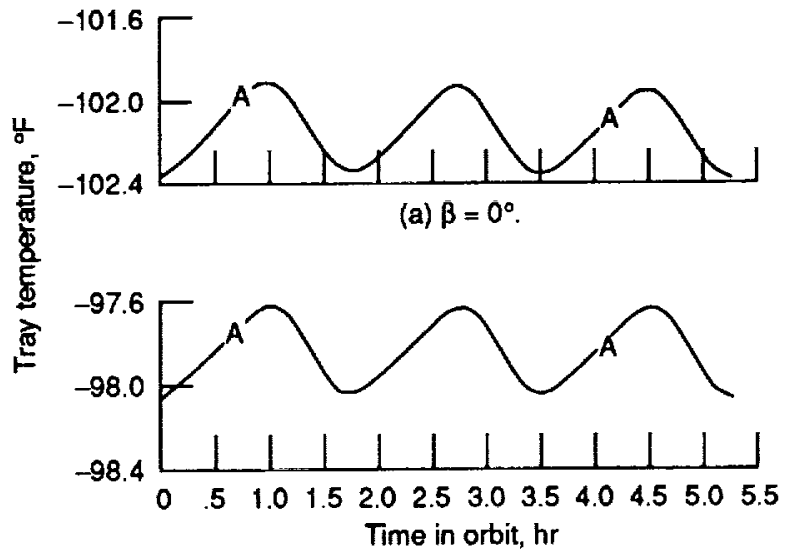

(b) $\beta=41^{\circ}$.

Figure 11. Plumbing tray temperatures for attitude "A".

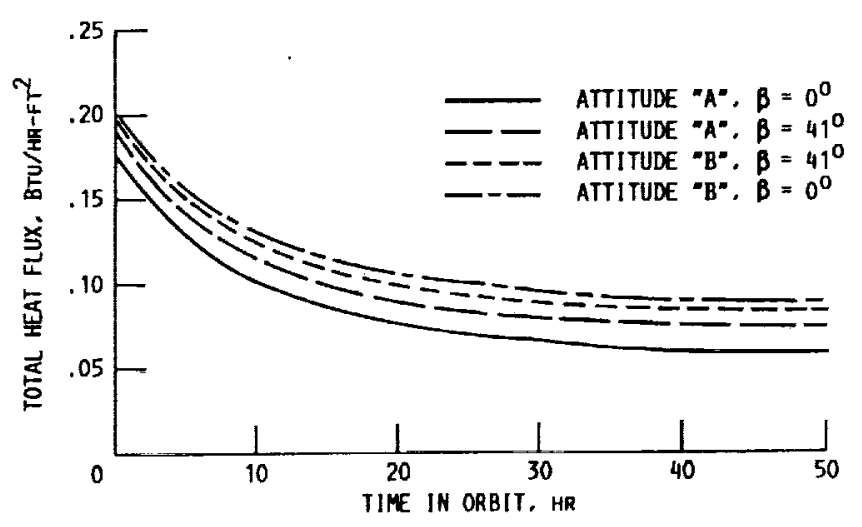

Figure 12.-Total heat flux on pressure vesselspacecraft attitude impacts. 


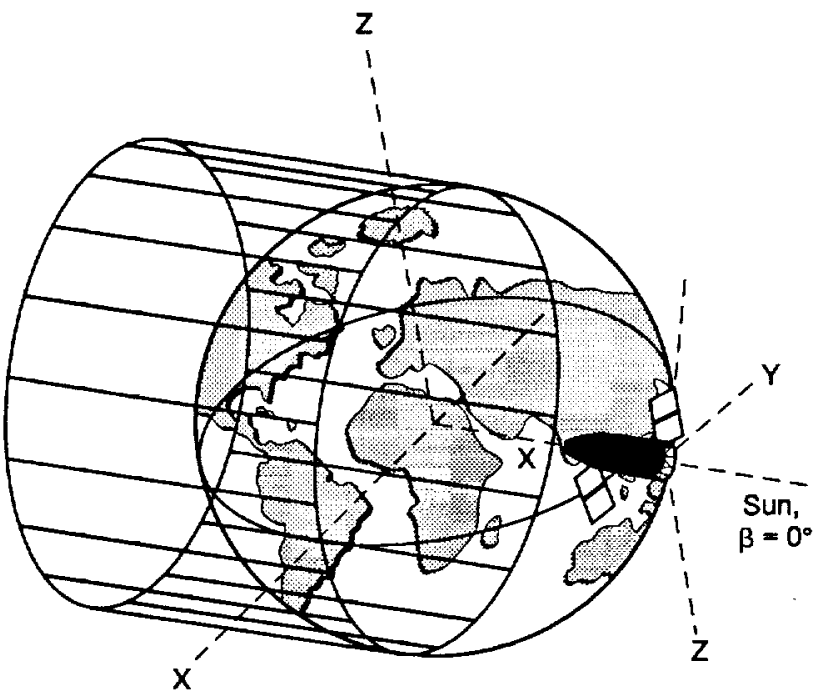

(a) Operational cold-case attitude and load shedding case attitude.

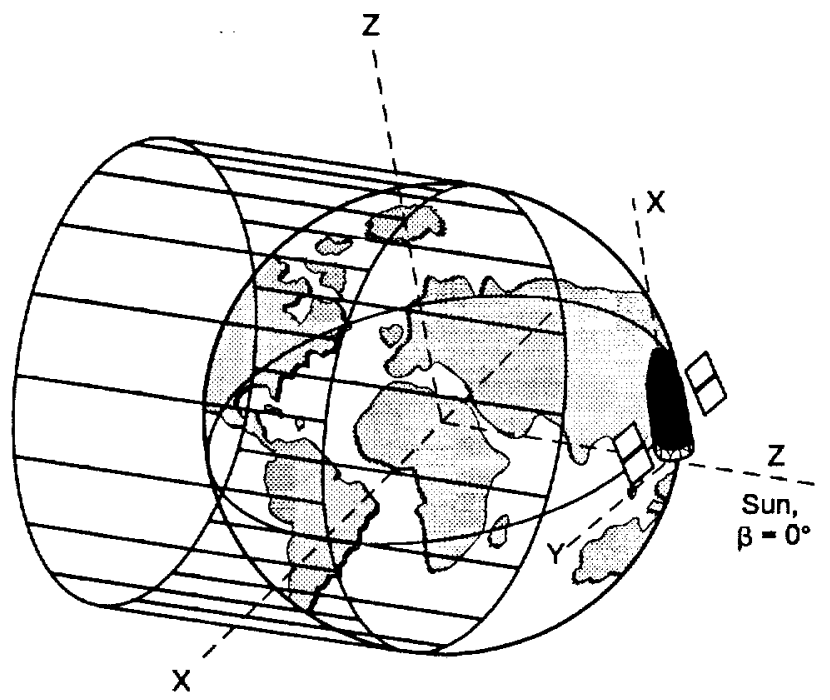

(b) Loss of attitude case (Sun on battery panel).

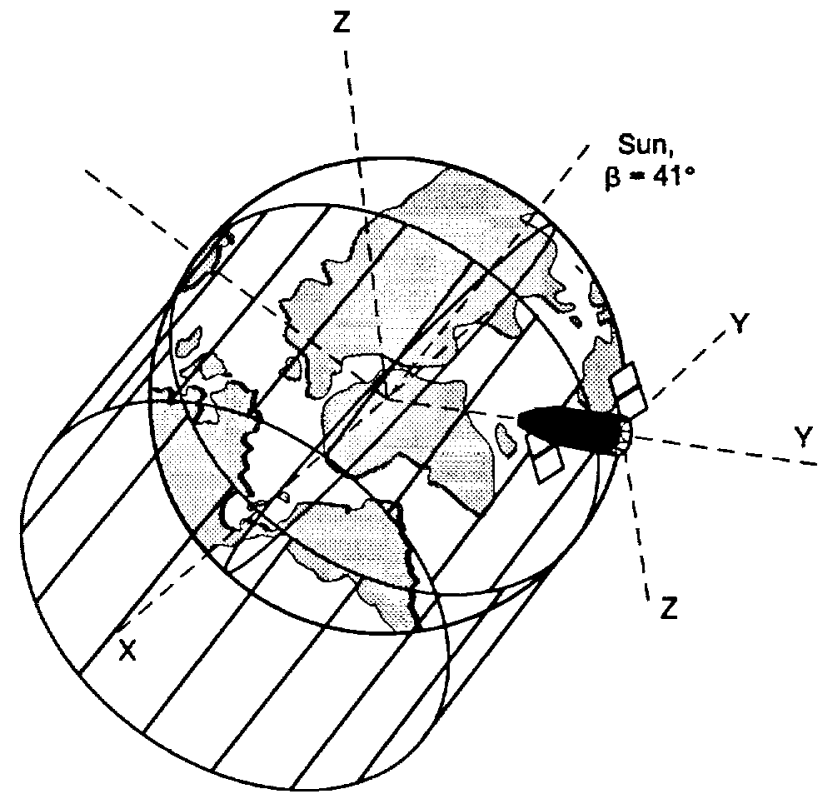

(c) Operational hot case attitude.

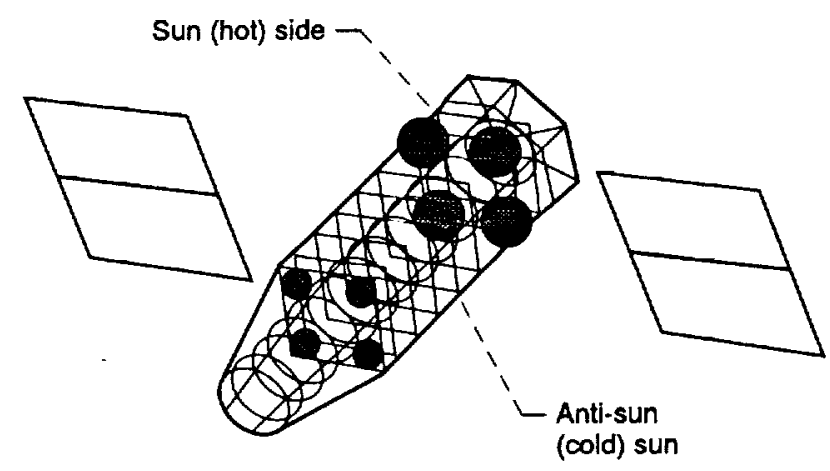

(d) Spacecraft external/exposed surfaces TRASYS model.

Figure 13.-Spacecraft orbital conditions for thermal analysis. 


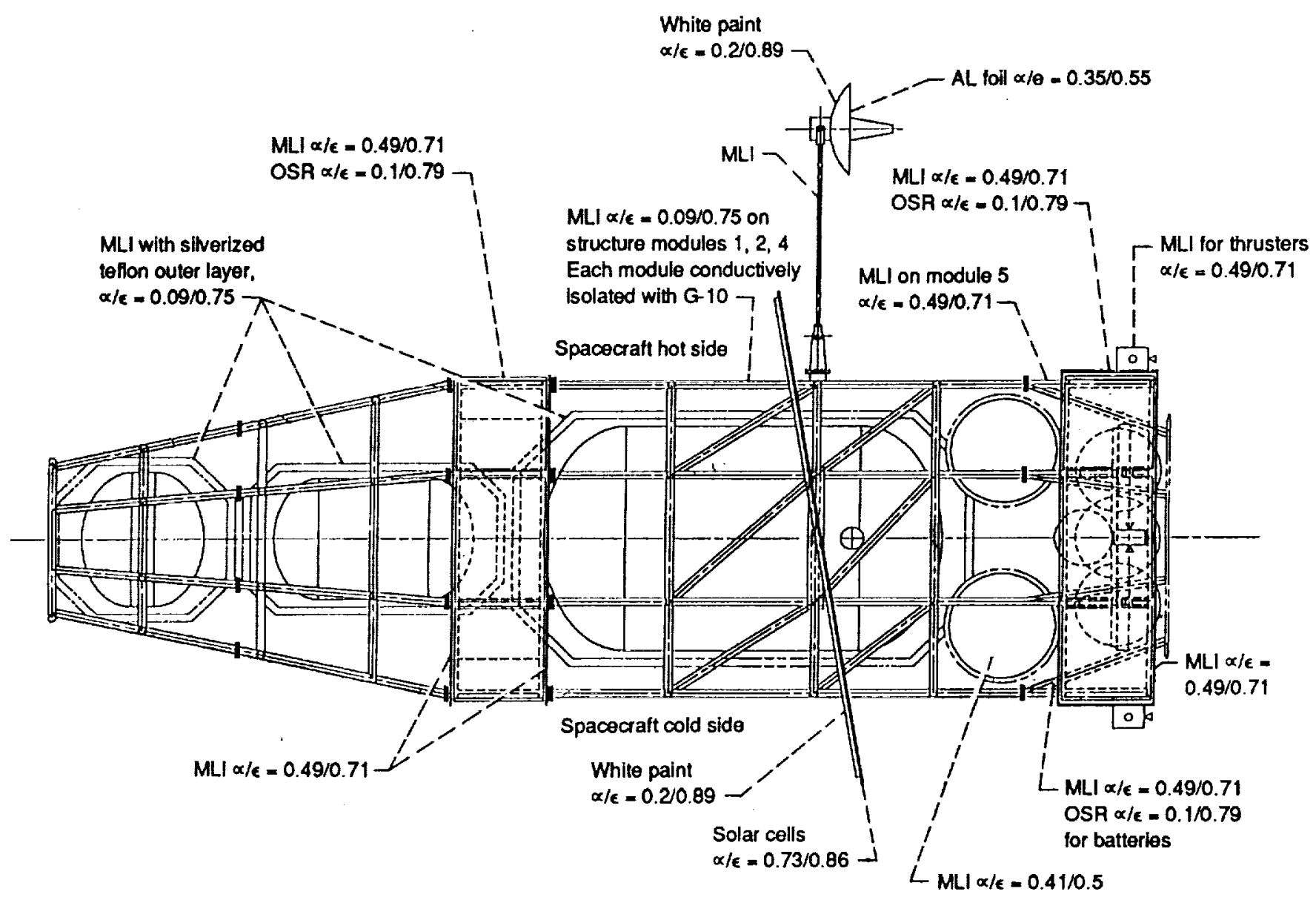

Figure 14.-COLD-SAT spacecraft exterior thermal control surfaces; thermo-optical properties. 


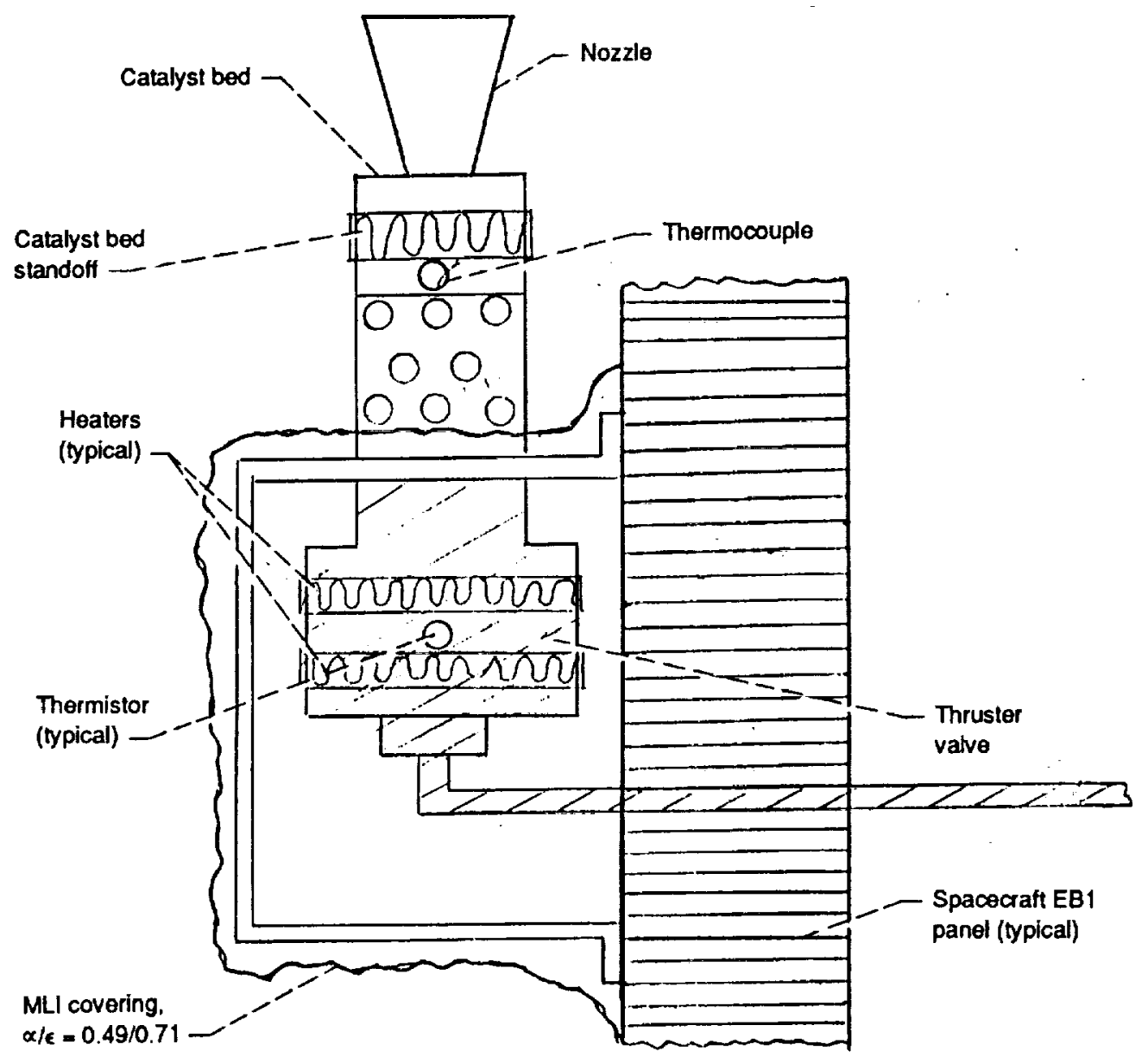

Figure 15.-Thruster module thermal control. 


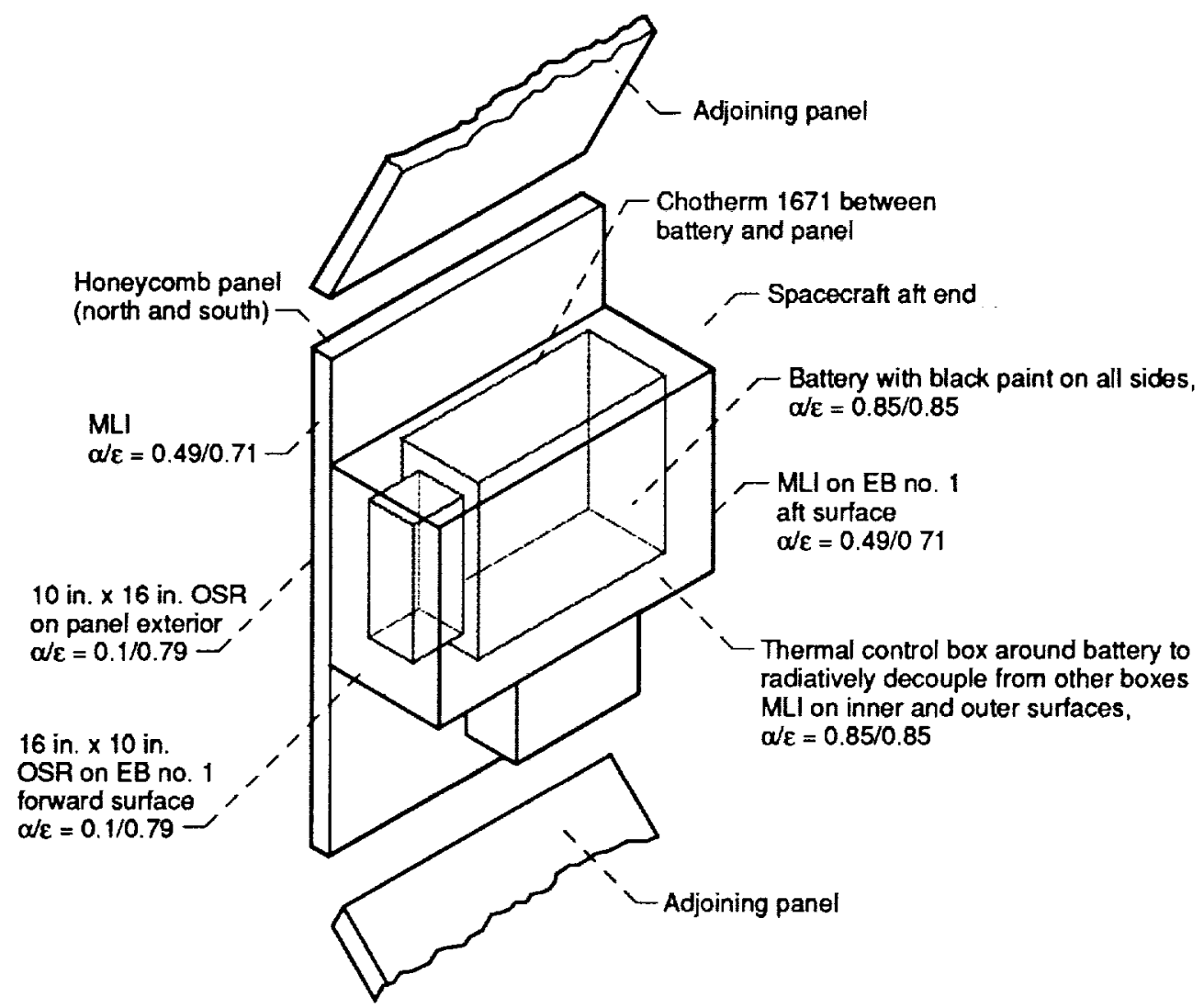

Figure 16.-Battery thermal control.

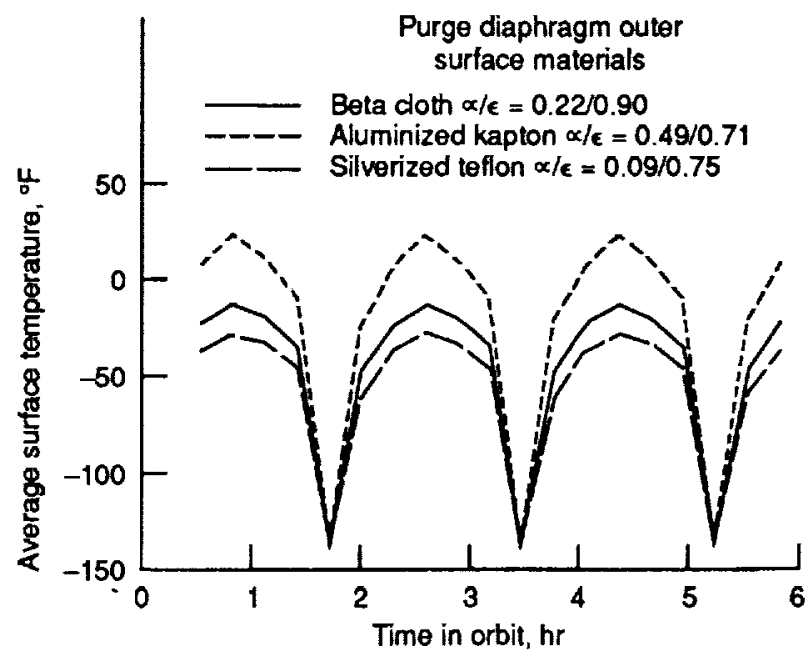

Figure 17. - Purge diaphragm average temperature outer surface material effects $\left(\beta=41^{\circ}\right)$.

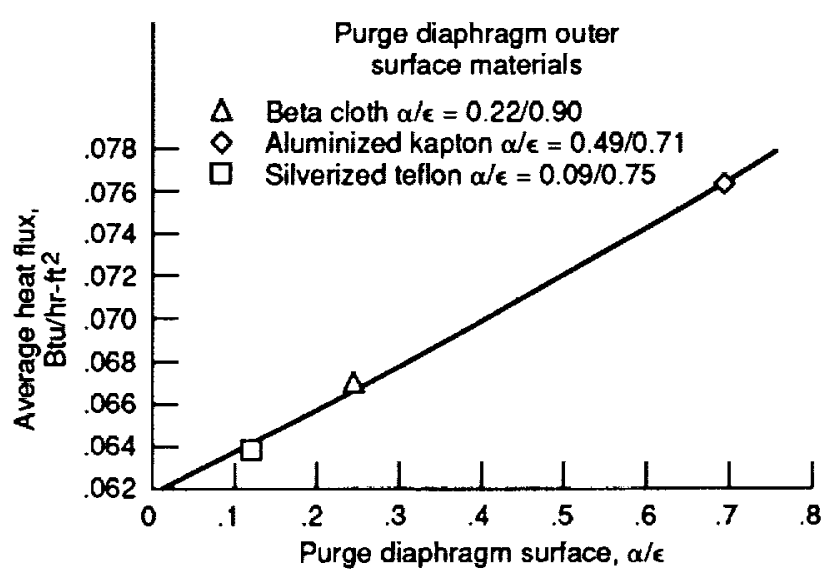

Figure 18.-Purge diaphragm surface effects on pressure vessel heat flux $\left(\beta=41^{\circ}\right)$. 


\begin{tabular}{|l|c|c|}
\hline \multirow{2}{*}{$\begin{array}{c}\text { Curve } \\
\text { summary }\end{array}$} & \multicolumn{2}{|c|}{$\begin{array}{c}\text { Temperature, } \\
\text { of }\end{array}$} \\
\cline { 2 - 3 } & Minimum & Maximum \\
\hline $\mathrm{A}=$ Tank support \\
plate & 55 & 58 \\
$\mathrm{~B}=$ Tank no. 1 & 56 & 57 \\
$\mathrm{C}=$ Tank no. 2 & 57 & 58 \\
$\mathrm{D}=$ Tank no. 3 & 56 & 57 \\
$\mathrm{E}=$ Tank no. 4 & 56 & 57 \\
\hline
\end{tabular}

\begin{tabular}{|c|c|c|}
\hline \multirow{2}{*}{$\begin{array}{c}\text { Curve } \\
\text { summary }\end{array}$} & \multicolumn{2}{|c|}{$\begin{array}{c}\text { Temperature, } \\
\text { of }\end{array}$} \\
\cline { 2 - 3 } & Minimum & Maximum \\
\hline $\mathrm{A}=$ Tank support \\
plate & 83 & 85 \\
$\mathrm{~B}=$ Tank no. 1 & 84 & 85 \\
$\mathrm{C}=$ Tank no. 2 & 83 & 85 \\
$\mathrm{D}=$ Tank no. 3 & 83 & 84 \\
$\mathrm{E}=$ Tank no. 4 & 83 & 84 \\
\hline
\end{tabular}

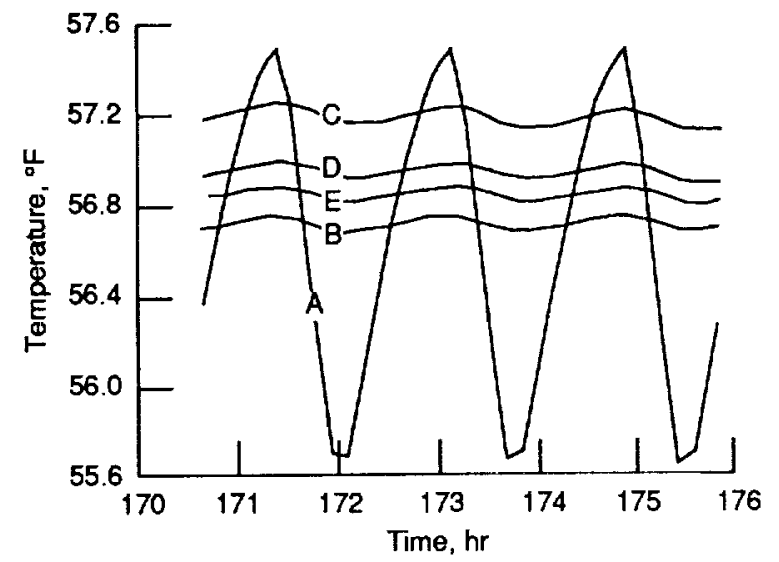

(a) Worst case cold, $\beta=0^{\circ}$.

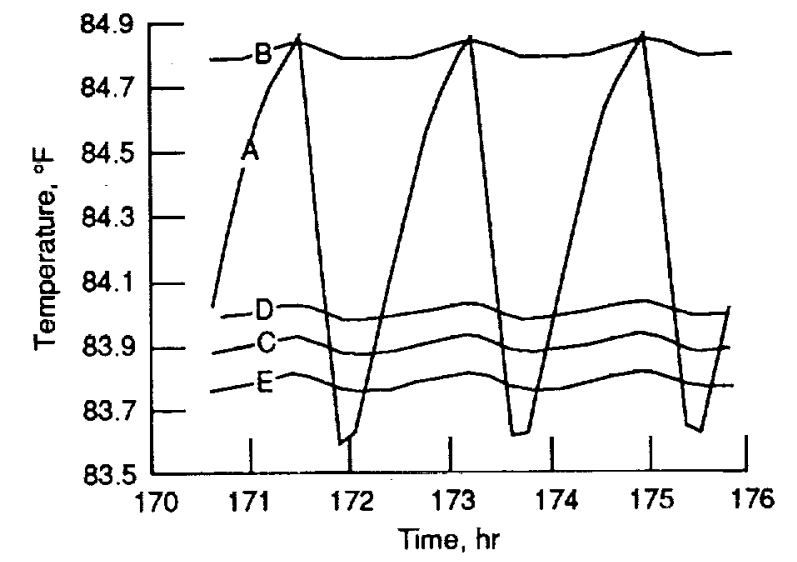

(b) Worst case hot, $\beta=41^{\circ}$.

Figure 19. - Hydrazine tank results for operational on-orbit case.

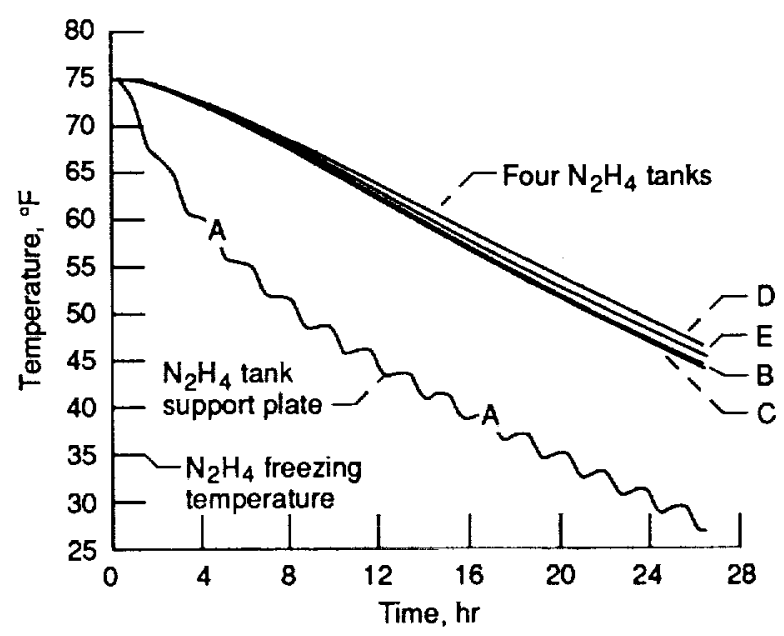

Figure 20.-Hydrazine tank results for load shedding case. 


\begin{tabular}{|c|c|c|}
\hline \multirow{2}{*}{$\begin{array}{c}\text { Curve } \\
\text { summary }\end{array}$} & \multicolumn{2}{|c|}{$\begin{array}{c}\text { Temperature, } \\
\text { oF }\end{array}$} \\
\cline { 2 - 3 } & Minimum & Maximum \\
\hline $\mathrm{A}=$ South panel & 48 & 50 \\
$\mathrm{~B}=$ Battery no. 2 & 48 & 50 \\
$\mathrm{C}=$ Motor drive elec. & 48 & 50 \\
$\mathrm{D}=$ Sun sensor no. 2 & 48 & 50 \\
elec. & & \\
\hline
\end{tabular}

\begin{tabular}{|c|c|c|}
\hline \multirow{2}{*}{$\begin{array}{c}\text { Curve } \\
\text { summary }\end{array}$} & \multicolumn{2}{|c|}{$\begin{array}{c}\text { Temperature, } \\
{ }^{\circ} \mathrm{F}\end{array}$} \\
\hline & Minimum & Maximum \\
\hline $\begin{array}{l}A=\text { South panel } \\
B=\text { Battery no. } 2 \\
C=\text { Motor drive elec. } \\
D=\text { Sun sensor no. } 2 \\
\text { elec. }\end{array}$ & $\begin{array}{l}77 \\
77 \\
77 \\
77\end{array}$ & $\begin{array}{l}79 \\
79 \\
79 \\
79\end{array}$ \\
\hline
\end{tabular}

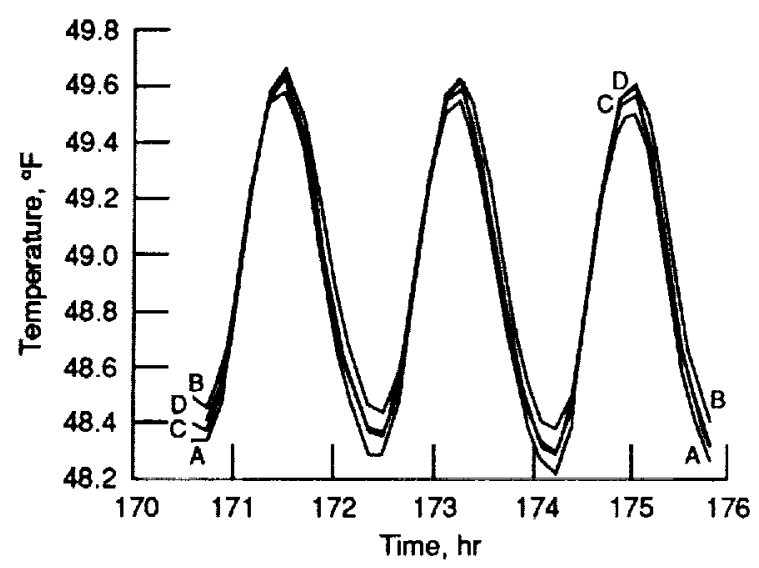

(a) Worst case cold, $\beta=0^{\circ}$.

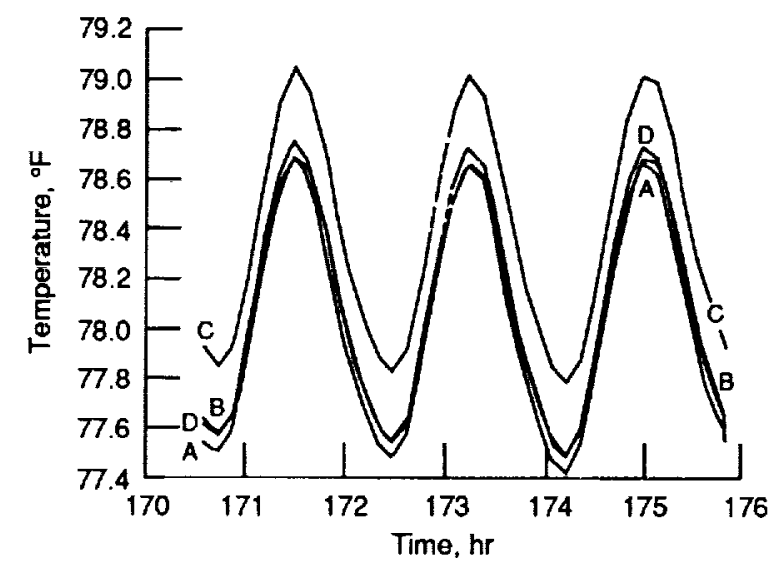

(b) Worst case hot, $\beta=41^{\circ}$.

Figure 21.-Battery no. 2 results for operational on-orbit case.

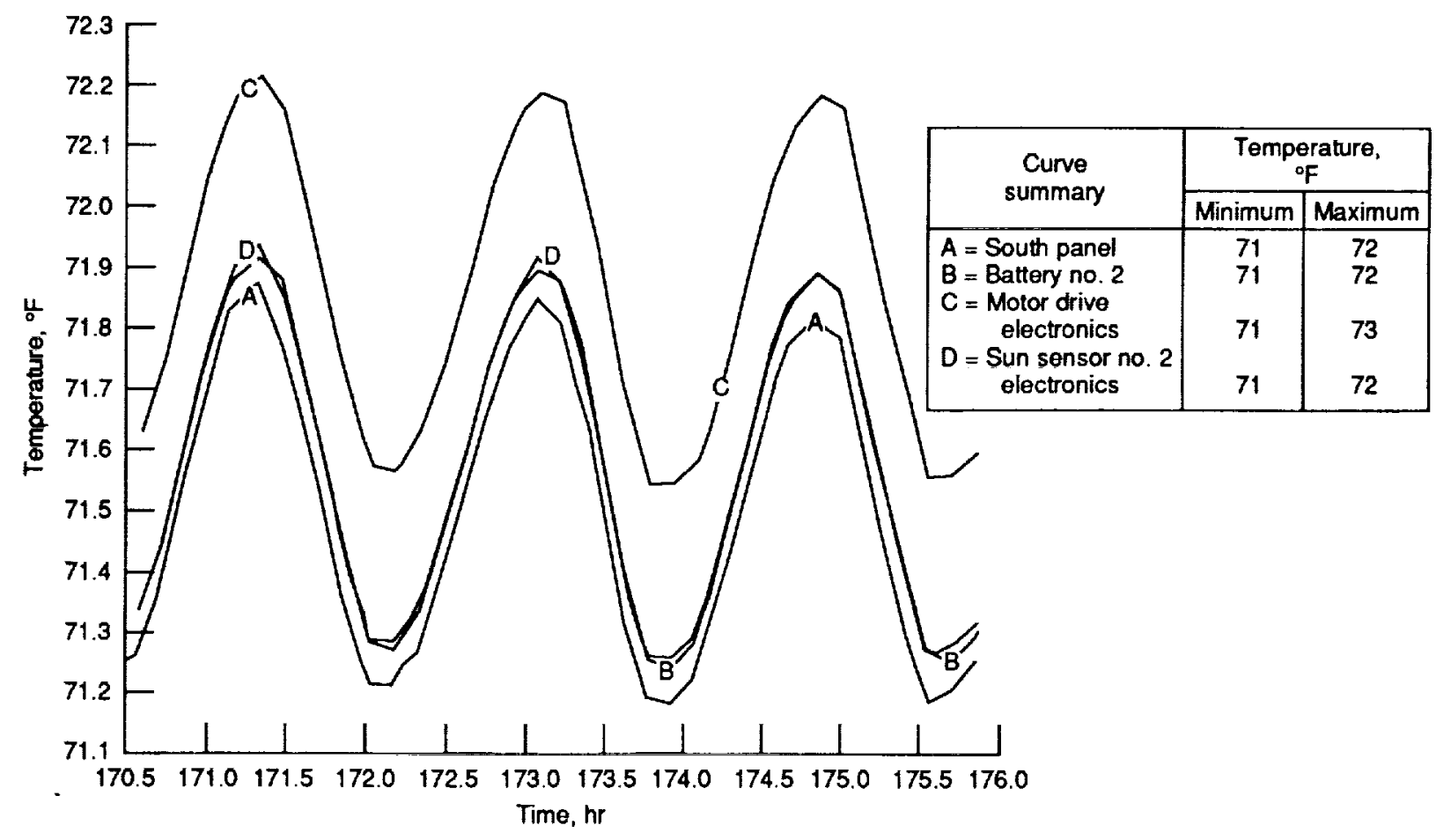

Figure 22.-Battery no. 2 results for loss of attitude case. 


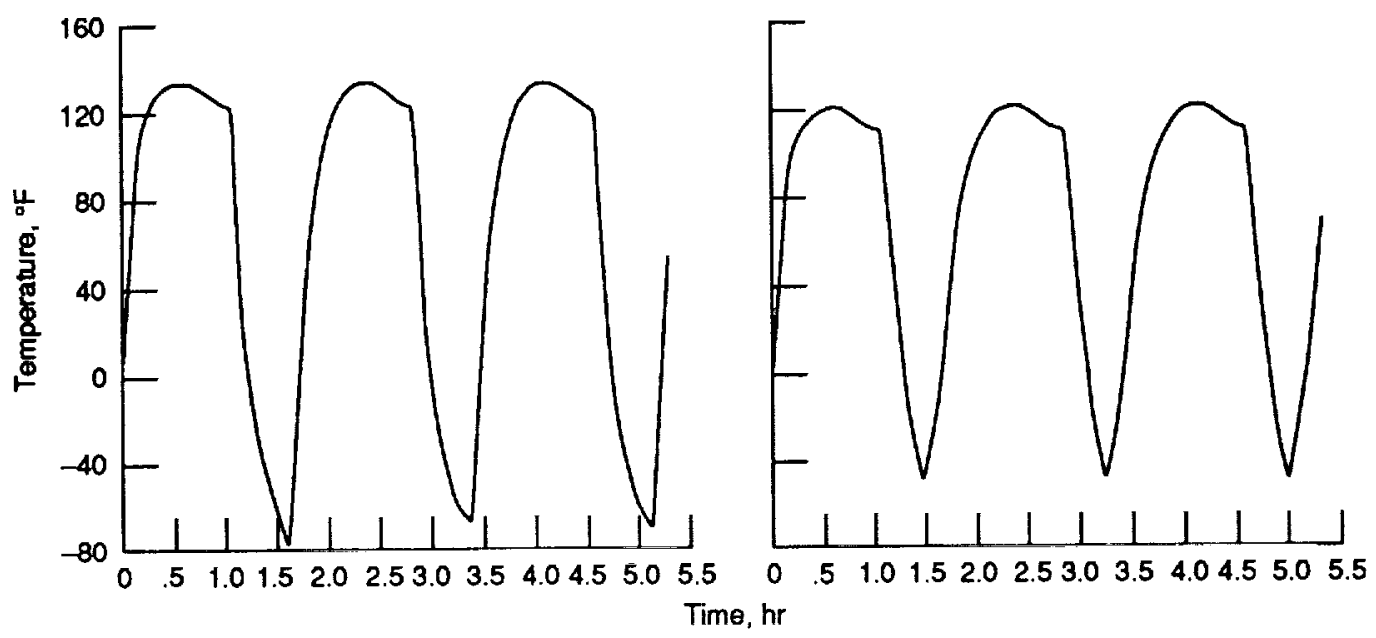

(a) $\beta=0^{\circ}$.

(b) $\beta=41^{\circ}$.

Figure 23. - Solar panel temperatures. 


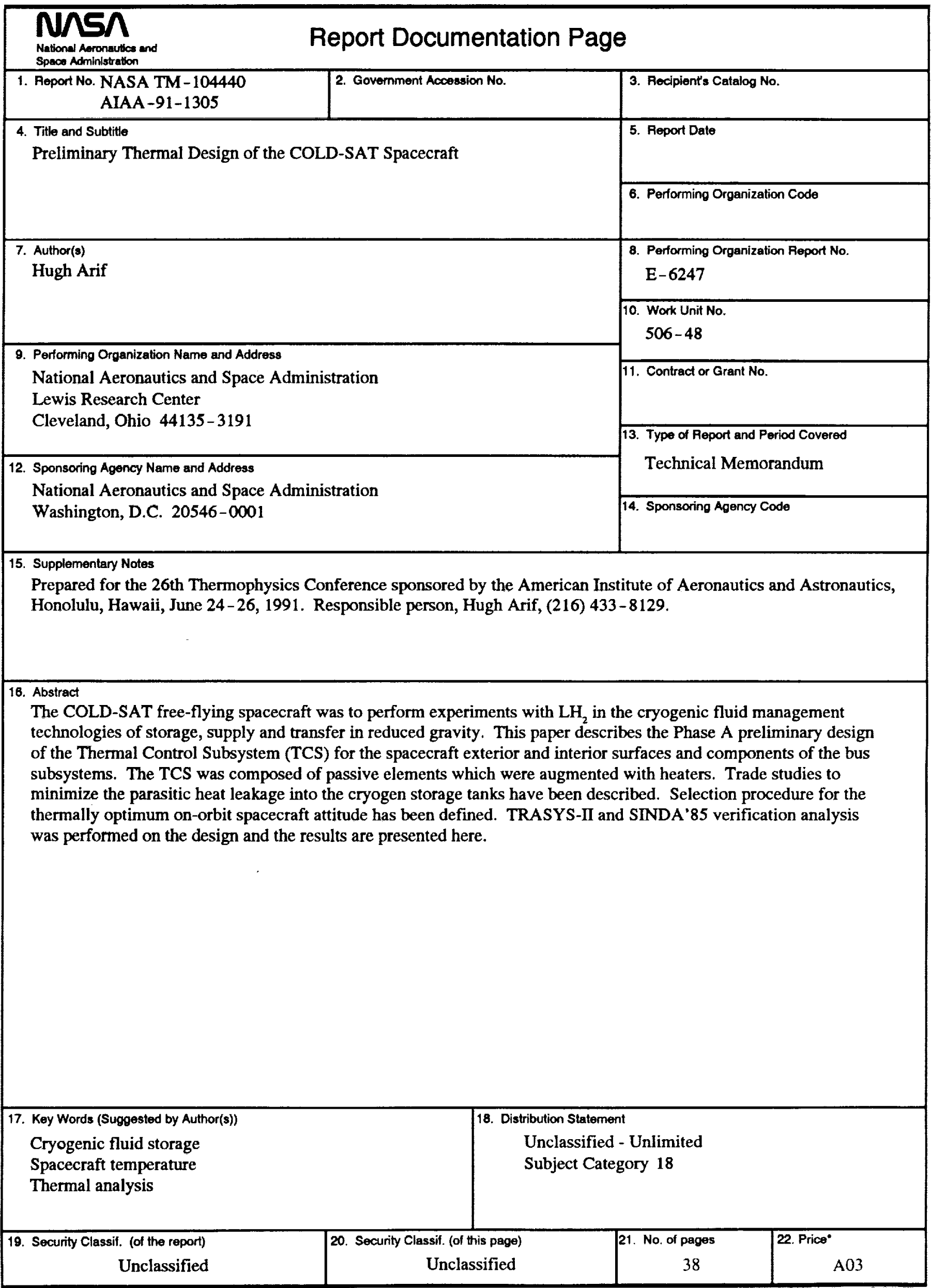

